\title{
Chemically modified cellulose nanocrystals as polyanion for preparation of polyelectrolyte complex
}

\author{
Niédja Fittipaldi Vasconcelos (D) Judith Pessoa Andrade Feitosa $\mathbb{D} \cdot$ \\ Fábia Karine Andrade (D) Marcus Aurélio Ribeiro Miranda (iD) José Marcos Sasaki $(\mathbb{D} \cdot$ \\ João Paulo Saraiva Morais (1) - Lorena Mara Alexandre e Silva $(\mathbb{D} \cdot$

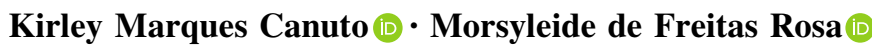

Received: 16 July 2018/ Accepted: 19 December 2018/ Published online: 1 January 2019

(C) Springer Nature B.V. 2019

\begin{abstract}
Bacterial cellulose nanocrystals (BCNCs) have hydrophilic surfaces due to hydroxyl groups but are water-insoluble. The carboxymethylation improves the solubility of cellulose in polar media through the insertion of carboxymethyl groups. This study aims to evaluate the use of two different alcoholic solvents in the carboxymethylation reaction of BCNCs: ethanol and isopropanol. BCNCs were obtained under two hydrolysis conditions: sulfuric acid (BCNC-S) and combination of sulfuric and hydrochloric acids (BCNC-S/Cl). Two techniques (NMR and titration) were used to determine the degree of substitution (DS) values. Carboxymethylation of $\mathrm{BCNC}-\mathrm{S} / \mathrm{Cl}$ led to high DS compared to
\end{abstract}

Electronic supplementary material The online version of this article (https://doi.org/10.1007/s10570-018-2223-3) contains supplementary material, which is available to authorized users.

N. F. Vasconcelos · J. P. A. Feitosa

Department of Chemistry, Federal University of Ceará

(UFC), Bloco 940, Fortaleza, Ceará 60451-970, Brazil

F. K. Andrade

Department of Chemical Engineering, Federal University of Ceará (UFC), Bloco 709, Fortaleza, Ceará 60455-760, Brazil

M. A. R. Miranda · J. M. Sasaki

Department of Physics, Federal University of Ceará

(UFC), Bloco 926, Fortaleza, Ceará 60455-970, Brazil
BCNC-S and the use of isopropanol promoted an even greater DS. The thermal properties were not affected after the chemical modification. However, functionalization provided an increase in the negative charge density at the surface of nanostructures and a change in the crystal structure (cellulose type $\mathrm{I}_{\alpha}$ for amorphous), making this material a potential polyanion for the synthesis of polyelectrolyte complexes (PECs). The micrographs showed that the nanocrystals became soluble after carboxymethylation. Carboxymethylated bacterial cellulose nanocrystals hydrolyzed through the mixture of inorganic acids and modified using isopropanol (CBCNC-S/Cl-IPA) was a suitable polyanion to produce PECs with chitosan. The PECs produced had particle size ranging from 276 to $588 \mathrm{~nm}$ and zeta potential ranging from -24.3 to $+39.0 \mathrm{mV}$.

\author{
J. P. S. Morais \\ Embrapa Algodão - CNPA, Rua Oswaldo Cruz 1143, \\ Centenário, Campina Grande, Paraíba 58428-095, Brazil \\ L. M. A. e Silva - K. M. Canuto . \\ Morsyleide de FreitasRosa $(\square)$ \\ Embrapa Agroindústria Tropical - CNPAT, Rua Dra. Sara \\ Mesquita 2270, Planalto do Pici, Fortaleza, \\ Ceará 60511-110, Brazil \\ e-mail: morsyleide.rosa@embrapa.br
}




\section{Graphical abstract}

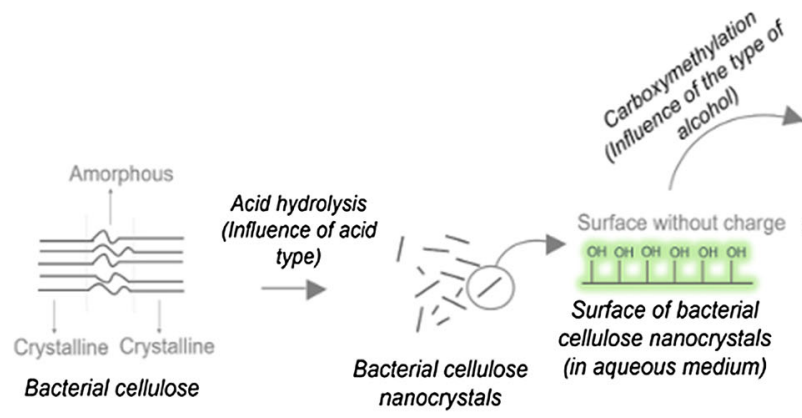

Keywords Bacterial cellulose $\cdot$ Hydrolysis . Nanocrystals · Carboxymethylation · Chitosan . Polyelectrolytic complexes

\section{Introduction}

Bacterial cellulose (BC) is synthesized by several genera of bacteria, such as Komagataeibacter (formerly classified as Gluconacetobacter), Rhizobium, Agrobacterium, Aerobacter, Salmonella, Escherichia, and Sarcina (Shoda and Sugano 2005; Chawla et al. 2009; Yamada et al. 2012; Picheth et al. 2017). However, bacteria from the genus Komagataeibacter synthesizes cellulose in higher quantities (Picheth et al. 2017). During biosynthesis, the cellulose is excreted by nanometric pores of the bacterial cell membrane forming a regular and uniform threedimensional structure composed of nanofibers (usually with width ranging $10-90 \mathrm{~nm}$ ) stabilized by hydrogen bonds, that exhibits interesting characteristics, such as high porosity, low density, high mechanical strength, biocompatibility, biodegradability, and high crystallinity (Krystynowicz et al. 2002; Pecoraro et al. 2008; Chawla et al. 2009; Gama et al. 2012; Gromovykh et al. 2017). Due to these properties, $\mathrm{BC}$ has attracted attention as a starting material for obtaining cellulose nanocrystals (CNCs), used in various applications, such as polymeric reinforcing agent (Pereira et al. 2014; Ng et al. 2015; Dufresne 2017), emulsion stabilizer (Yan et al. 2017; Zhou et al. 2018), suture biomaterial (Wu et al. 2018a), among other (Grishkewich et al. 2017).

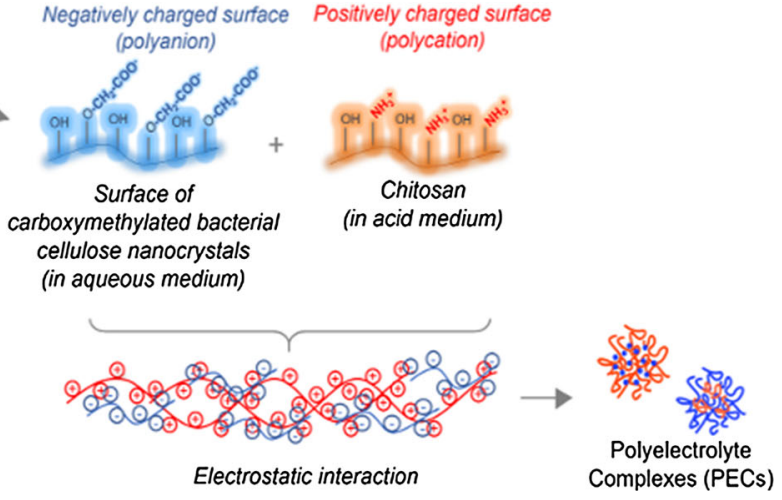

The nanocrystals are generally obtained by acid hydrolysis, in which strong acids, such as sulfuric acid and/or hydrochloric acid, are used. Many studies have been conducted to obtain bacterial cellulose nanocrystals (BCNCs) by this process (Roman and Winter 2004; Moreira et al. 2009; Guo and Catchmark 2012; Vasconcelos et al. 2017). Regardless of the type of process used, these crystals should have a nanoscale dimension (1-100 nm), usually their width, and are fascinating "building blocks" for several applications (Charreau et al. 2013).

$\mathrm{BC}$ and $\mathrm{CNCs}$ are completely insoluble in water and in most organic solvents, limiting their applications. However, cellulosic material has a hydrophilic surface due of the high quantity of free hydroxyl groups $(-\mathrm{OH})$. These groups are highly reactive and offer the great possibility of surface chemical modification (Dufresne 2012). Therefore, chemical modification of cellulose can be extended similarly to cellulose nanocrystals (Ibrahim et al. 2011; Cha et al. 2012; Seabra et al. 2018).

Chemical modification of nanocrystals aims to adjust the hydrophilic-hydrophobic balance on the surface of the nanostructures to obtain a cellulosic product with suitable functional properties for the desired application (Habibi 2014). Derivatization is based on replacing the hydroxyls by organic groups. Theoretically, the structure of the CNC exhibits three reactive sites on the D-glucopyranose unit. These points are the hydroxyls on carbons 2,3 , and 6 . The properties of the modified product depend mainly on two factors: the type of inserted functional group and the degree of substitution (DS). Several chemical modifications of cellulose have been reported, such as 
sulfonation (Gu et al. 2013; Lin and Dufresne 2014), oxidation (Coseri et al. 2013), esterification (Ramírez et al. 2014), amidation (Meng and Edgar 2015), and acetylation (Das et al. 2014). For the CNCs, the literature reports acetylation (Wu et al. 2018b) and other modifications to make CNCs hydrophobic (Shang et al. 2018; Ferreira et al. 2018). However, the most commonly used chemical modification of cellulose is etherification via carboxymethylation. This derivatization improves the aqueous dispersion/solubilization of cellulose. In the literature the most exploited source of cellulose (Qi et al. 2009; Yeasmin and Mondal 2015; Santos et al. 2015; Candido and Gonçalves 2016) and CNCs (Cha et al. 2012; Ma et al. 2017) is cellulose extracted from plants. However, the chemical modification in bacterial cellulose science is poorly investigated (Casaburi et al. 2018). In addition, the carboxymethylation of bacterial cellulose nanocrystals was not reported in the literature.

Based on Williamson reaction, the carboxymethylation of cellulose is carried out in two steps. In the first step (alkalinization), the pulp cellulose is treated with an excess of sodium hydroxide in the presence of a non-aqueous solvent, usually an alcohol. In the second step (etherification), the alkaline cellulose reacts with monochloroacetic acid (MCAA) or sodium monochloroacetate (SMCA), generating carboxymethylcellulose (CMC) as the final product (Togrul and Arslan 2004; Habibi 2014). Chemically, the carboxymethylation reaction is based on nucleophilic substitution. In the alkalinization step, the base and the solvent enhance the nucleophilic character of hydroxyl groups. The formed alkoxy groups ($\mathrm{O}^{-} \mathrm{Na}^{+}$) attack the electrophilic carbon in the etherifying agent. The type of alcohol used in the reaction may directly influence the values of DS and the dispersibility/solubility of the cellulose, since a higher DS results in greater solubility in water of the carboxymethylated product. Therefore, the carboxymethylated cellulose is usually obtained and used in the form of a sodium salt and when dissolved in water has typical characteristics of a polyelectrolyte, in this case, as polyanion due of the presence of the carboxymethyl group $\left(-\mathrm{CH}_{2} \mathrm{COO}^{-}\right)$on its surface.

Polyanion (highly negatively charged) when in contact with opposite charge (polycation) such as chitosan originate polyelectrolyte complexes (PECs) by electrostatic attraction. In addition to the charge, to occur complexation (interlacing and entanglement) between the polymer chains it is necessary that they be solubilized in the medium (polar or non-polar). Such complexes may be used to prepare nanoparticulate systems, which may be in the form of nanospheres or nanocapsules. In this context, carboxymethylcellulose, from plant sources, has been widely used as polyanion, along with chitosan, in applications involving controlled drug release systems (Bigucci et al. 2015). Other polycations with CMC from plant were used in the preparation of membrane separation (Liu et al. 2014), delivery system of negatively charged proteins and DNA vaccines (Song and Chen 2015). Thus, the carboxymethylation of CNC promotes the formation of polyanions that when complexed are $\mathrm{pH}$ responsive (Cha et al. 2012). In addition to offering smaller sized PECs. However, there are no previous studies involving the preparation of PECs using carboxymethylated cellulose nanocrystals of bacterial origin and chitosan. The nanocomplexes obtained from $\mathrm{BC}$ have the advantage of high purity. In this way, the material will be more adequate to biomedical applications (e.g. as suit the regulatory agencies) (Lankalapalli and Kolapalli 2009; Vehlow et al. 2016).

Therefore, this study aims to investigate whether the BCNC extraction process and the type of alcoholic solvent influence the carboxymethylation of BCNCs and its properties. Moreover, the potential of carboxymethylated bacterial cellulose nanocrystals (CBCNC) as a polyanion in the preparation of polyelectrolyte complexes was evaluated as an example of successful chemical modification.

\section{Materials and methods}

The flowchart shown in Fig. 1 represents a summary of the stages developed in the present work. Briefly, BC membranes were initially disintegrated by Ultraturrax (Physical Deconstruction). Then, the cellulosic material was hydrolyzed with strong acids $\left(\mathrm{H}_{2} \mathrm{SO}_{4}\right.$ and $\mathrm{HCl}$ ) to obtain the BCNCs (Extraction of nanocrystals). BCNCs were chemically modified through the carboxymethylation reaction, investigating the influence of two types of alcohol solvents (ethanol and isopropanol) used in the reaction medium (Carboxymethylation). From the characterization of $\mathrm{CBCNC}$, the condition with the highest degree of 
Fig. 1 Flowchart of the steps developed in the present work
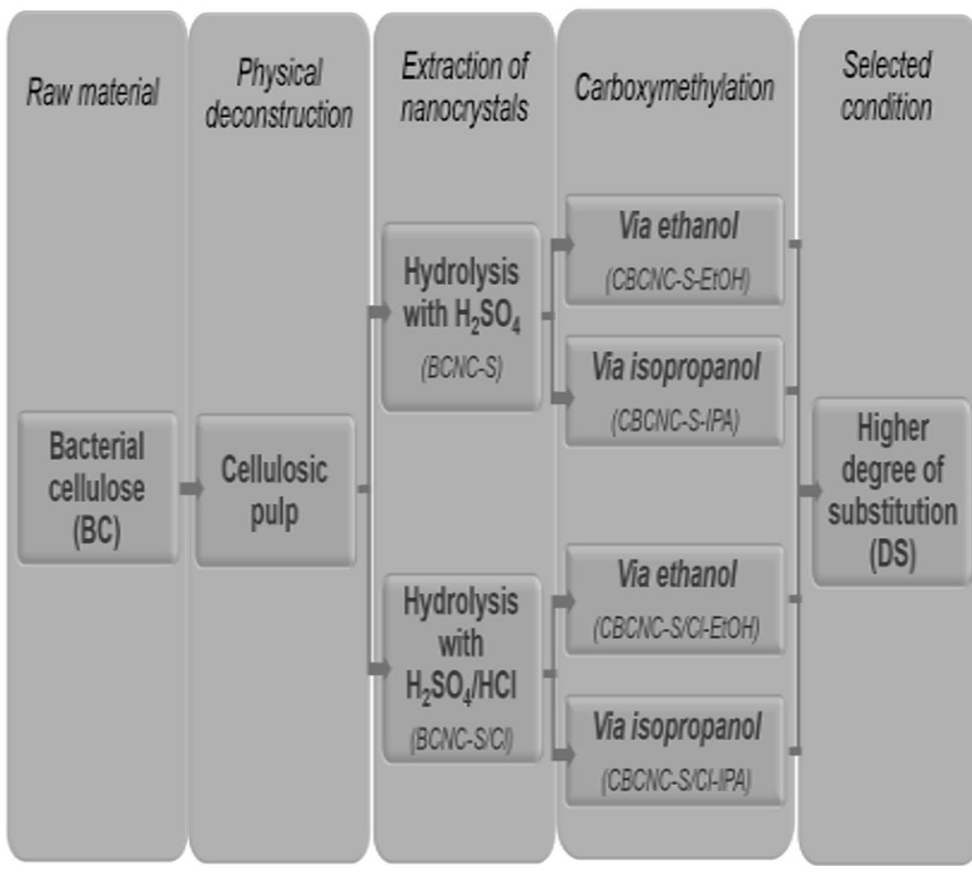

substitution, that is, greater quantity of groups available for interaction (Selected condition) was selected to be used in the preparation of nanoparticles via polyelectrolytic complexation (PECs) (Nanoparticulate Synthesis).

\section{Materials}

The bacterial cellulose (BC) used in this study was obtained from HTK Food Company, Ltd. (Ho Chi Minh City, Vietnam).

Sodium hydroxide (code 221465), sulfuric acid (code 258105), hydrochloric acid (code 320331), monochloroacetic acid (code 402923), glacial acetic acid (code 695092), isopropyl alcohol (code 278475), and chitosan (code 48165) were purchased from Vetec ${ }^{\mathrm{TM}} /$ SigmaAldrich. Ethyl alcohol (code 00A1083.09.BJ) and methyl alcohol (code 01A1085.01.BL) were purchased from Synth. Dideuterated sulfuric acid (code 176796), deuterium oxide (code 151882) were purchased from Sigma-Aldrich. Chitosan (degree of deacetylation of $76 \%$ ) was purchased from Polymar. All the analytical grade reagents were used without further purification and as received from the supplier.
Methods

\section{Physical deconstruction}

BC hydrated membranes (15 mm of thickness and $98 \%$ of moisture) were maintained in $0.4 \%(\mathrm{w} / \mathrm{v})$ $\mathrm{NaOH}$ at room temperature for $24 \mathrm{~h}$, then washed with distilled water until neutralization to remove any chemicals used in the BC-preparation process and any possible microbial, protein, or lipid contamination. BC membranes were cut into small cubes $\left(5 \mathrm{~mm}^{3}\right)$ and processed in an Ultra-Turrax homogenizer (T50 basic/ S50 N-G45G/IKA ${ }^{\circledR}$ ) at $10,160 g$ for 5 min to obtain a cellulosic pulp. This slurry was filtered through quantitative filter paper $(8 \mu \mathrm{m})$ and freeze-dried (K105, Liotop, Brazil). The lyophilized BC was transformed into powder by grinding analytical mill (A11 basis/IKA ${ }^{\circledR}$ ) and stored in a glass container. Methodology described by Vasconcelos et al. (2017).

\section{Extraction of nanocrystals/BCNCs}

The BC powder was used as the starting material for the extraction of BCNCs. The conditions were selected according to an earlier work and reports in the literature (Vasconcelos et al. 2017). Two acidic hydrolysis conditions were used in this study: (1) 
hydrolysis with $50 \%$ (w/w) $\mathrm{H}_{2} \mathrm{SO}_{4}$ for 60 min (referred as $B C N C-S)$; and (2) hydrolysis with $60 \%$ (w/ w) $-(34 \%, \mathrm{w} / \mathrm{v})-\mathrm{H}_{2} \mathrm{SO}_{4}$ and $37 \%(\mathrm{w} / \mathrm{w})-(24 \%$, w/v)$\mathrm{HCl}$ for $60 \mathrm{~min}$ (referred as $\mathrm{BCNC}-\mathrm{S} / \mathrm{Cl}$ ). The values in parentheses indicate the real concentrations of the acids in the reaction medium, due to the dilution caused using $\mathrm{HCl}$ P.A., in which it presents a high percentage of water.

In brief, for each experiment, $5 \mathrm{~g}$ of $\mathrm{BC}$ powder and $500 \mathrm{~mL}$ of acid solution (ratio 1:100 w/v) were mixed at $45^{\circ} \mathrm{C}$ for $60 \mathrm{~min}$ under magnetic stirring at 2030 $g$. After hydrolysis, reactions were stopped by diluting the system 15 -fold with cold deionized water. Each suspension was centrifuged (Himac CR22III/ R13A, Hitachi, Japan) at 26,400g for $15 \mathrm{~min}$ at $20{ }^{\circ} \mathrm{C}$ to precipitate the BCNCs. The BCNCs were washed with deionized water and centrifuged at $26,400 \mathrm{~g}$ for $15 \mathrm{~min}$ at $20^{\circ} \mathrm{C}$. This process was repeated three times. Finally, the BCNC suspension was treated with ultrasound for $3 \mathrm{~min}$ (Disruptor $60 \mathrm{kHz} ; 300 \mathrm{~W}$, Unique, Brazil) and dialyzed (Spectra/Por 5, 12-14 $\mathrm{kD}$ ) until neutral $\mathrm{pH}$. The suspension showed a final concentration of 1\% (w/v) (Vasconcelos et al. 2017).

\section{Carboxymethylation of $\mathrm{BCNCs}$}

The procedure used for the carboxymethylation reaction was carried out heterogeneously, as described by Ibrahim et al. (2011) with some modifications. First, $30 \mathrm{~mL}$ of BCNC suspension was added to $90 \mathrm{~mL}$ of alcoholic solvent $(1: 3 \mathrm{v} / \mathrm{v})$. Then, $10 \mathrm{~mL}$ of $\mathrm{NaOH}$ $60 \%(\mathrm{w} / \mathrm{w}$ ) was added dropwise over $30 \mathrm{~min}$, at room temperature, under magnetic stirring (500 rpm). After addition of $\mathrm{NaOH}$, the reaction proceeds for $1 \mathrm{~h}$. Following this first step, $6.5 \mathrm{~g}$ of monochloroacetic acid was dissolved in $15 \mathrm{~mL}$ of alcoholic solvent and added dropwise over $30 \mathrm{~min}$ to the system. The mixture was heated to $60^{\circ} \mathrm{C}$ for $2 \mathrm{~h}$, under magnetic stirring $(500 \mathrm{rpm})$. Finally, the suspension was centrifuged at 26,400 $g$ for $15 \mathrm{~min}$ for phase separation. The settled material was resuspended in $150 \mathrm{~mL}$ of methanol 70\% (v/v) and neutralized with glacial acetic acid. The suspension was filtered and washed three times with anhydrous methanol and dried at $60{ }^{\circ} \mathrm{C}$ in a vacuum oven.

The alcoholic solvents studied were chosen by two criteria: first, through the results obtained by Pushpamalar et al. (2006), in which ethanol (EtOH) and isopropanol (IPA) were the solvents that substituted the cellulose. Second, in the highly stable structure of nanocrystals (which tends to be more difficult to replace than cellulose). BCNC-S carboxymethylated with IPA and EtOH was identified as CBCNC-S-IPA and CBCNC-S-EtOH, respectively. Similarly, the $\mathrm{BCNC}-\mathrm{S} / \mathrm{HCl}$ derivatives were identified as CBCNC-S/Cl-IPA and CBCNC-S/Cl-EtOH. The reaction to obtain each sample was performed twice.

\section{Synthesis of nanoparticles/PECs}

Carboxymethylated bacterial cellulose nanocrystals (CBCNCs) and chitosan solutions (Ch) were prepared at concentration of $0.1 \%(\mathrm{w} / \mathrm{v})$. The chitosan solution was prepared by dissolving $0.5 \mathrm{~g}$ in $22 \mathrm{~mL}$ of $0.105 \mathrm{~mol} \mathrm{~L}^{-1} \mathrm{HCl}$ under magnetic stirring (2000 rpm) for $24 \mathrm{~h}$ at room temperature. To prepare the CBCNC solution, $0.5 \mathrm{~g}$ of the modified nanocrystals were dissolved in deionized water. The solution was then heated at $40{ }^{\circ} \mathrm{C}$ for $10 \mathrm{~min}$ for complete solubilization of the sample. Both solutions had their pH adjusted to 4, using $0.105 \mathrm{~mol} \mathrm{~L}^{-1} \mathrm{NaOH}$ and $\mathrm{HCl}$ solutions. The ionic strength was corrected to $0.05 \mathrm{~mol} \mathrm{~L}^{-1}$ by the addition of $1 \mathrm{~mol} \mathrm{~L}^{-1} \mathrm{NaCl}$ solution. After, each solution was completed with deionized water in a $500 \mathrm{~mL}$ volumetric flask. Finally, both solutions were filtered using a $0.45 \mu \mathrm{m}$ cellulose acetate membrane.

For the formation of the PECs, pre-determined volumes of the $\mathrm{Ch}$ and CBCNCs solutions were used, as shown in Table 1. The preparation was performed by slow and constant drip of the solution using a graduated burette and under magnetic stirring. The influence of the ratio of positive and negative charges $\left(\mathrm{q}^{+} / \mathrm{q}^{-}=0.5,1\right.$ and 5$)$, as well as the effect of addition order of the components (addition of polyanion to polycation and polycation to polyanion) on complex formation were evaluated in this work.

Table 1 Volumes of $\mathrm{Ch}$ and $\mathrm{CBCNCs}$ solutions at $0.1 \%(\mathrm{w} / \mathrm{v})$ and the charge ratios of the PECs produced

\begin{tabular}{lll}
\hline $\begin{array}{l}\text { Charge ratio } \\
\left(\mathrm{q}^{+} / \mathrm{q}^{-}\right)\end{array}$ & $\begin{array}{l}\text { Volume of } \mathrm{Ch} \\
\text { solution }(\mathrm{mL})\end{array}$ & $\begin{array}{l}\text { Volume of CBCNCs } \\
\text { solution }(\mathrm{mL})\end{array}$ \\
\hline 0.5 & 2.4 & 41.4 \\
1 & 4.8 & 20.7 \\
5 & 24.2 & 4.1 \\
\hline
\end{tabular}


Characterizations

\section{Fourier transform infrared (FTIR) spectroscopy}

BCNCs and CBCNCs spectra were obtained using a 660 IR FTIR instrument (Varian; Mulgrave, Australia) in transmittance mode. The resolution was set at $4 \mathrm{~cm}^{-1}$, and 100 scans were collected in the $4000-400 \mathrm{~cm}^{-1}$ spectral region. Before analysis, the samples were ground and pelletized using $\operatorname{KBr}(1: 100$, w/w), followed by uniaxially pressure.

\section{Degree of substitution (DS)}

DS of CBCNCs were obtained through two different techniques: titration and Nuclear magnetic resonance (NMR), described below.

Titration To calculate the DS by the titration method (DS-TITR), the samples were modified to an acid form, based on method A (acid wash) of ASTM 1439-15 (2015). Initially, $0.125 \mathrm{~g}$ of dry CBCNCs was weighed and $25 \mathrm{~mL}$ of deionized water was added. The solution was left under magnetic stirring (1000 rpm) for $30 \mathrm{~min}$ and then heated at $40{ }^{\circ} \mathrm{C}$ for more $15 \mathrm{~min}$ to ensure complete dissolution in water. After cooling, $30 \mathrm{~g}$ of Amberlite IRA-120 (conditioned in acid form) cation exchange resin was added in CBCNCs solution and kept under magnetic stirring for $30 \mathrm{~min}$. Finally, the solution was filtered and freeze-dried. For the titration, $0.05 \mathrm{~g}$ of CBCNCs in the acid form were added in $10 \mathrm{~mL}$ of deionized water and $2.5 \mathrm{~mL}$ of $0.5038 \mathrm{~mol} \mathrm{~L}^{-1} \mathrm{NaOH}$. The solution was heated at $40{ }^{\circ} \mathrm{C}$ for $15 \mathrm{~min}$ under magnetic stirring and titrated with $0.5172 \mathrm{~mol} \mathrm{~L}^{-1}$ $\mathrm{HCl}$, using phenolphthalein as indicator. Reference samples were treated in similar way. The titration of carboxymethylated samples was performed in triplicate and, percentage of carboxymethyl (CMC) and DS-TITR values were calculated using the equations below (Eqs. 1 and 2) (Elomaa et al. 2004; Pushpamalar et al. 2006).

$$
\begin{aligned}
\% \mathrm{CMC}= & {\left[162 \times\left(\mathrm{V}_{\mathrm{HCl}}-\mathrm{V}_{\text {blank }}\right)\right.} \\
& \left.\times \mathrm{M}_{\mathrm{HCl}} \times 0.058 \times 100\right] / \mathrm{m}
\end{aligned}
$$

DS-TITR $=162 \times \% \mathrm{CMC} /[5800-(57 \times \% \mathrm{CMC})]$ where: $\mathrm{V}_{\mathrm{HCl}}$ is volume of $\mathrm{HCl}$ used to titrate sample $(\mathrm{mL}), \mathrm{V}_{\text {blank }}$ is volume of $\mathrm{HCl}$ used to titrate blank $(\mathrm{mL}), \mathrm{M}_{\mathrm{HCl}}$ is the concentration in $\mathrm{mol} \mathrm{L}^{-1}$ of used $\mathrm{HCl}, \mathrm{m}$ is amount of dry sample $(\mathrm{g}), 162$ is the molar mass of cellulose unit, and 58 is molar mass of carboxymethyl group in the acid form.

NMR The one-dimensional ${ }^{1} \mathrm{H}$ spectra of carboxymethylated BCNCs were acquired on an DD2 spectrophotometer (Agilent; California, USA), operating at a hydrogen frequency of $599.94 \mathrm{MHz}$, equipped with a $5 \mathrm{~mm}$ hybrid detection multinuclear probe $(\mathrm{HF} / 15 \mathrm{~N}-31 \mathrm{P})$ and field gradient in the $\mathrm{z}$-axis, applying a single $90^{\circ}$ pulse followed by spectral acquisition. The spectra were obtained at $26{ }^{\circ} \mathrm{C}$, with a delay time between each acquisition of $6.86 \mathrm{~s}, 32$ transients in a spectral window of $16 \mathrm{ppm}, 66 \mathrm{k}$ number of points and a waiting time between each acquisition of $30 \mathrm{~s}$. The ${ }^{1} \mathrm{H}$ signal for the methyl group of acetic acid at $2.11 \mathrm{ppm}$ was used as the internal reference standard for calibration of the spectra.

For the two-dimensional gradient selected COSY spectrum (gCOSY), 16 transients were obtained, with a waiting time between each acquisition of $1 \mathrm{~s}$, with a spectral width in F1 and F2 of 8 ppm, and with many points in the acquisition between 200 and 715, respectively.

The DS of the CBCNCs was determined by ${ }^{1} \mathrm{H}$ NMR. Each CBCNC sample (30 mg) was hydrolyzed in $500 \mu \mathrm{L}$ of a mixture of $\mathrm{D}_{2} \mathrm{O} / \mathrm{D}_{2} \mathrm{SO}_{4}(2: 1, \mathrm{v} / \mathrm{v})$. The hydrolysis occurred in an appropriate glass tube (Wilmad) at $90{ }^{\circ} \mathrm{C}$ for $2 \mathrm{~h}$. After the reaction, $1 \mu \mathrm{L}$ of acetic acid was added to the tube as an internal reference standard (Ho and Klosiewicz 1980). The DS was calculated by the ratio between the integral area related to methylene protons from the carboxymethyl group and the sum of integral areas related to the proton linked to the $\mathrm{C} 1$ carbon of the $\mathrm{D}$-glucopyranose free ring (Eq. 3).

$\mathrm{DS}-\mathrm{NMR}=(\mathrm{a} / 2) / \mathrm{b}$

where a-integral area related to methylene protons from the carboxymethyl group, which corresponds to the signals $4.20 \leq \delta \leq 4.56 \mathrm{ppm} ; \mathrm{b}$ - the sum of integral areas related to the proton bound to $\mathrm{C} 1$ of the D-glucopyranose ring unit, which corresponds to the signals $5.26 \mathrm{ppm}$ (singlet) and $4.69 \mathrm{ppm}$ (duplet). 
Furthermore, the two-dimensional homonuclear gCOSY experiment was used for selecting the best spectral area to be integrated for the D-glucopyranose molecule.

\section{$X$-ray diffraction $(X R D)$}

The X-ray powder diffraction measurements were done in a Xpert Pro MPD-PANalytical diffractometer, with CoK $\alpha$ radiation $(\lambda=1.789 \AA)$ and operating at $40 \mathrm{kV}$ and $40 \mathrm{~mA}$ in parallel beam geometry using a hybrid monochromator composed of one mirror and two Ge (220) crystals. Each diffraction pattern was taken in $60 \mathrm{~min}$ with $2 \theta$ ranging from $10^{\circ}$ to $50^{\circ}$ in steps of $0.13^{\circ}$.

The calculation of crystallinity index (CrI) for BC was obtained in accordance to Segal et al. (1959) (Eq. 4).

$\operatorname{CrI}(\%)=\left(\mathrm{I}_{200}-\mathrm{I}_{a m}\right) / \mathrm{I}_{200}$

where: $\mathrm{I}_{200}-$ maximum intensity of the diffraction major peak, located in angle $2 \theta \sim 26.7^{\circ}$; and $\mathrm{I}_{a m}-$ minimum intensity between diffraction major peak, located in the angle $2 \theta \sim 22.5^{\circ}-23^{\circ}$.

The crystallite size (CS) of the purified $\mathrm{BC}$ was calculated using the Scherrer's equation (Eq. 5) (Scherrer 1918).

$\mathrm{CS}=\mathrm{K} \lambda / \mathrm{FWHM} \times \operatorname{Cos}(\theta)$

where: $\mathrm{K}$ is a constant that depends on the crystal shape (in the case 0.94$) ; \lambda$ is the wavelength of the incident $X$-ray $(\lambda=0.17889 \mathrm{~nm}) ; \theta$ is the Bragg angle of the reflection under consideration. The full width at half maximum (FWHM, in radians) were obtained by fitting the diffraction peaks with a pseud-Voigt function and the software used for this purpose was the Xpert High Score from PANalytical (Degen et al. 2014). The effect of instrumental broadening was negligible for the wide peaks of purified BC.

\section{Zeta potential}

Each CBCNCs sample (1 g) was suspended in $100 \mathrm{~mL}$ of distilled water $(1 \%, w / \mathrm{v})$ at $\mathrm{pH} 7$ and placed in ultrasound batch $(1400 \mathrm{~A} 40 \mathrm{kHz}$, Unique, Brazil) for $15 \mathrm{~min}$ at $25^{\circ} \mathrm{C}$. For the PECs, $1 \mathrm{~mL}$ of each sample with concentration $0.1 \%(\mathrm{w} / \mathrm{v})$, at $\mathrm{pH} 4$, were collected for measurement. The surface charge density was measured in the Zetasizer Nano-ZS ZEN
3600 (Malvern Instruments Ltd.; Worcestershire, United Kingdom). The Smoluchowski algorithm was used to perform the calculations. The readings were performed in triplicate.

\section{Thermogravimetric analysis (TGA)}

The thermogravimetric profile of approximately $11 \mathrm{mg}$ of each CBCNC samples was obtained with a thermal analyzer, model STA 6000 (Perkin Elmer; Shelton, USA), scanning from 50 to $800{ }^{\circ} \mathrm{C}$ at a heating rate of $10{ }^{\circ} \mathrm{C} \mathrm{min}-1$ and under synthetic air atmosphere of $40 \mathrm{~mL} \mathrm{~min}{ }^{-1}$. The TGA curves were derived in the Origin Pro 8.5 software to obtain the differential thermogravimetry (DTG) curves.

\section{Differential scanning calorimetry (DSC)}

DSC curves were obtained using a DSC using an Q20 DSC (TA Instruments; New Castle, USA). The samples $(\cong 2.5 \mathrm{mg}$ ) were scanned from 30 to $350{ }^{\circ} \mathrm{C}$ with a heating rate of $10^{\circ} \mathrm{C} \mathrm{min}{ }^{-1}$, under a nitrogen atmosphere $\left(50 \mathrm{~mL} \mathrm{~min}{ }^{-1}\right)$. The variation in the amount of energy of the carboxymethylcellulose decomposition reaction $\left(\Delta \mathrm{H}_{d}\right)$ was calculated as the integral of the exothermic peak areas using TA Analysis software.

\section{Transmission electronic microscopy (TEM)}

Aqueous suspensions of nanocrystals before and after functionalization were sonicated for $15 \mathrm{~min}$, and 10 $\mu \mathrm{L}$ of each suspension was deposited in grids $(300$ mesh copper, formvar-carbon) and held for $10 \mathrm{~min}$. Excess liquid was removed with filter paper, and the samples were stained with phosphotungstic acid solution $(1 \%, \mathrm{w} / \mathrm{v})$, and then vacuum-dried for $24 \mathrm{~h}$. TEM micrographs were obtained using Tecnai G2 Spirit/Biotwin (FEI Company; Óregon, USA) with an acceleration voltage of $80 \mathrm{kV}$, in the Research Center Aggeu Magalhães, Oswaldo Cruz Foundation (FIOCRUZ). The length (L), width (D) and ratio aspect (L/ D) of the CBCNCs were determined from at least 100 measurements by the image analyzer, using Gimp 2.8 Software and from the obtained values the mean and standard deviation were calculated. 


\section{Size and distribution of particles}

The mean size and distribution of nanoparticles obtained through polyelectrolytic complexation were determined by dynamic light scattering (DLS) using the Zetasizer Nano-ZS ZEN 3600 (Malvern Instruments Ltd.; Worcestershire, United Kingdom), with red light beam and length of $633 \mathrm{~nm}$ wave. For this analysis, $1 \mathrm{~mL}$ PECs $(0.1 \%$, w/v) were collected and placed in polystyrene cuvettes at $25{ }^{\circ} \mathrm{C}$. For each sample, 10 readings were taken to calculate the mean value and the standard deviation.

\section{Results and discussion}

\section{Proof of substitution}

FTIR spectra of all studied materials are shown in Fig. 2. All spectra show typical cellulose absorption bands, indicating the presence of common functional groups. The principal absorption bands are observed at $3371 \mathrm{~cm}^{-1}$ (due to the stretching vibration of the $\mathrm{O}-\mathrm{H}$ bond because of the intra- and intermolecular interactions) and at $2907 \mathrm{~cm}^{-1}$ (attributed to the stretching vibration of the $\mathrm{C}-\mathrm{H}$ bond observed in the glucopyranose chain structure). The bands at $\sim 1429$ and $\sim 1316 \mathrm{~cm}^{-1}$ correspond to the angular deformation of the $-\mathrm{CH}_{2}$ and $-\mathrm{OH}$ groups, respectively. Finally, the bands at $1163 \mathrm{~cm}^{-1}$ and $897 \mathrm{~cm}^{-1}$ (indicated by an arrow) are attributed to the asymmetrical and flexion stretching of the $\beta$-glycosidic bond $(\mathrm{C}-\mathrm{O}-\mathrm{C})$, respectively, in the polymer chain (Chang and Chen 2016; Kian et al. 2018). The spectra of the functionalized nanocrystals feature a strong new absorption band between 1600 and $1650 \mathrm{~cm}^{-1}$ (highlighted in gray in Fig. 2), characteristic of the carboxylate $\left(-\mathrm{COO}^{-}\right)$asymmetrical stretching vibration from the insertion of a carboxymethyl group ($\mathrm{CH}_{2} \mathrm{COO}^{-}$) into the molecule (Pushpamalar et al. 2006; Rachtanapun et al. 2012). The presence of this new absorption band in the spectra of the CBCNCs confirms the etherification of the nanostructures.

Degree of substitution

From the FTIR spectra of CBCNCs it is possible to obtain a qualitative correlation on DS. As previously observed, the appearance of the vibration band

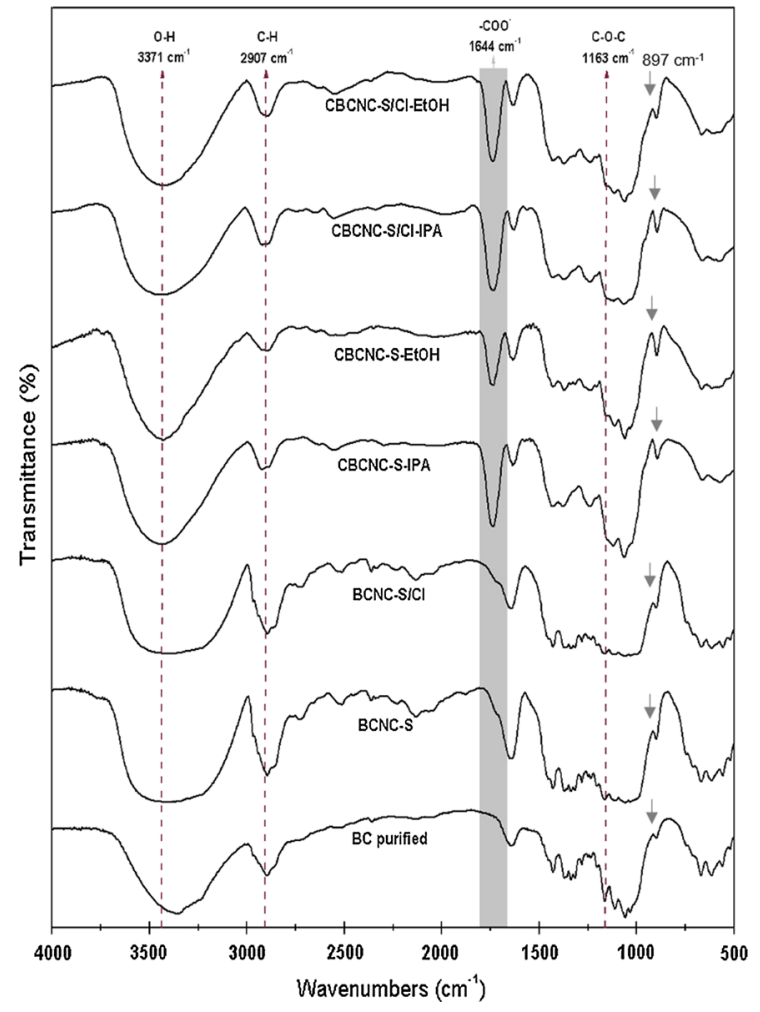

Fig. 2 FTIR spectrum of purified BC and BCNCs before and after functionalization by carboxymethylation

Table 2 DS (by two different techniques) results of the BCNCs after carboxymethylation

\begin{tabular}{lll}
\hline Sample & DS-NMR & DS-TITR \\
\hline CBCNC-S/Cl-EtOH & 1.3 & $1.29 \pm 0.02$ \\
CBCNC-S-IPA & 1.0 & $1.25 \pm 0.01$ \\
CBCNC-S/Cl-IPA & 1.5 & $1.50 \pm 0.05$ \\
\hline
\end{tabular}

(1600-1650 $\mathrm{cm}^{-1}$ ) corresponding to the carboxylate showed different intensities, indicating that BCNCs had different DS. CBCNC-S/Cl-EtOH and CBCNC-S/ Cl-IPA showed the most intense vibration band than CBCNC-S-EtOH and CBCNC-S-IPA, indicating that the greater insertion of $-\mathrm{COO}^{-}$groups in the structure CBCNC-S/Cl.

Two different techniques used were sensitive in the quantification of DS. Table 2 shows the results obtained by the methods employed. It can be observed that the results provided presented the same tendency, where the type of $\mathrm{BCNC}$ used in the modification and 


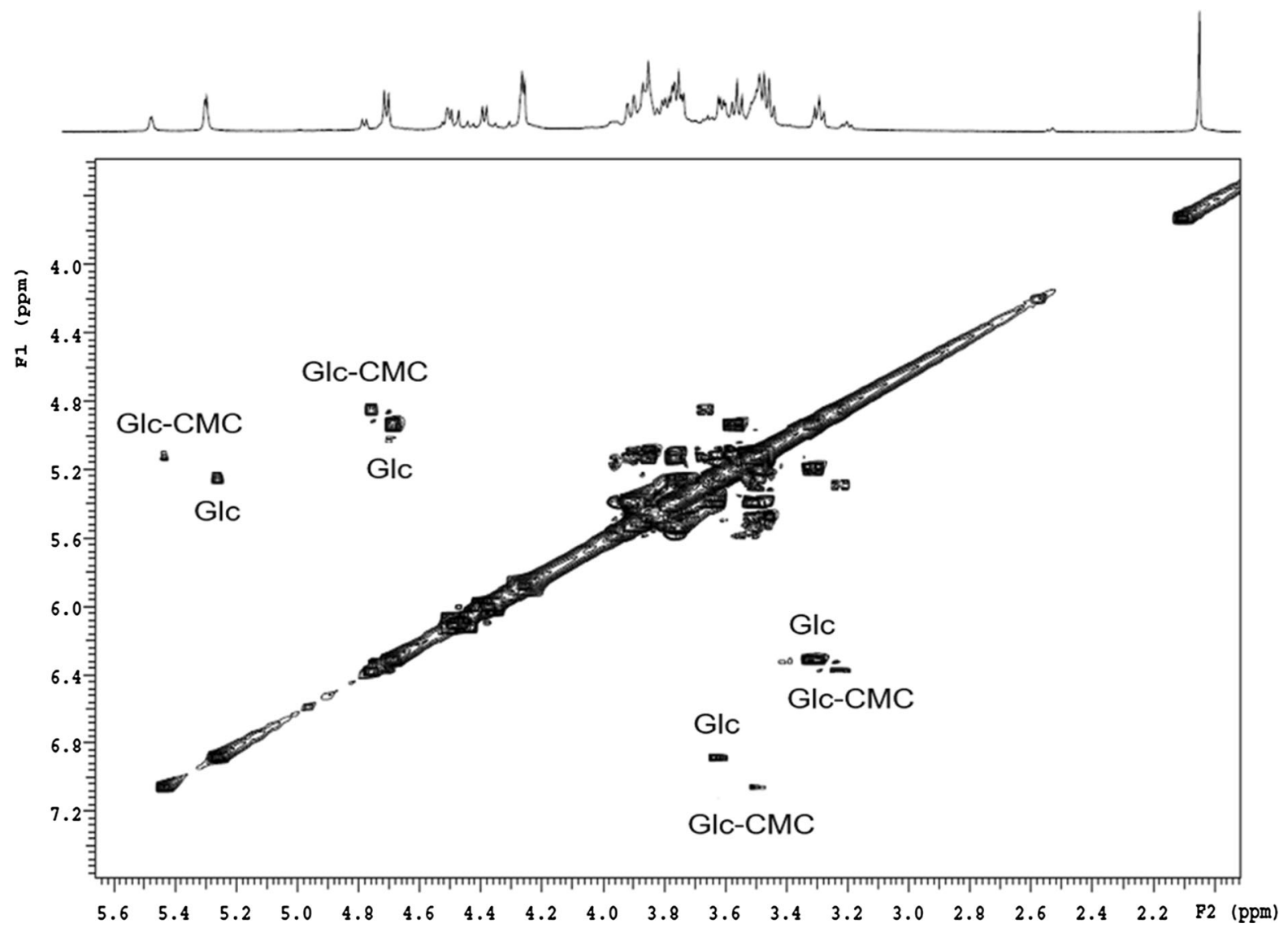

Fig. 3 COSY spectrum of carboxymethylated bacterial cellulose nanocrystals $(\mathrm{Glc}=$ glucose and Glc-CMC $=$ carboxymethylated glucose)

the type of alcoholic solvent influenced in the substitution reaction. On the techniques, the NMR method should offer absolute DS values. Therefore, the DS-NMR results were compared with the DS obtained by titration (DS-TITR).

The DS obtained from the ${ }^{1} \mathrm{H}-\mathrm{NMR}$ spectra was calculated using the ratio of the integral of the carboxymethyl spectral area represented by "a", and the integral of the free glucose proton area, represented by "b". The "b" value can be obtained by two methods: taking the direct sum of the set of two doublets at low field (single proton on the $\mathrm{C} 1$ ) or using $1 / 6$ of the total integral area of the main ${ }^{1} \mathrm{H}$ signals at high field (protons on the $\mathrm{C} 2, \mathrm{C} 3, \mathrm{C} 4, \mathrm{C} 5$ and C6). The "b" value is usually obtained by averaging the two individual measures, whose values are typically close (Ho and Klosiewicz 1980). The two-dimensional COSY spectrum obtained for the CBCNC is depicted in Fig. 3. There is a relationship between the signals of the ${ }^{1} \mathrm{H}$ carboxymethyl group and the free glucopyranose in the region from 2.8 to $3.8 \mathrm{ppm}$ in the $\mathrm{F} 2$ axis. Thus, the integral area of that region of the ${ }^{1} \mathrm{H}$ spectrum would not be valid for measuring the " $b$ " value. Therefore, "b" was calculated from the sum of the whole of the areas of the signals from 5.26 to $4.68 \mathrm{ppm}$ in the $\mathrm{F} 1$ axis, which are representative of $\mathrm{C} 1$ protons of $\alpha$-glucopyranose and $\beta$-glucopyranose, respectively.

The ${ }^{1} \mathrm{H}$ spectra and their respective integrated areas, used to calculate the value of the DS, are shown in Fig. 4.

Comparing the values of DS-NMR and DS-TITR it can be observed that the results were different only for the samples modified from the BCNC-S. A possible cause of this discrepancy between the techniques can be attributed to the quantification of the sulfate groups during the titration of the samples. According to Vasconcelos et al. (2017) the nanocrystals obtained by 
Fig. $4{ }^{1} \mathrm{H}$ NMR spectra of CBCNCs: a CBCNC-S$\mathrm{EtOH}$; b CBCNC-S/ClEtOH; c CBCNC-S-IPA; and $\mathbf{d}$ CBCNC-S/Cl-IPA.

The integrated area used to calculate the DS are highlighted in the axes

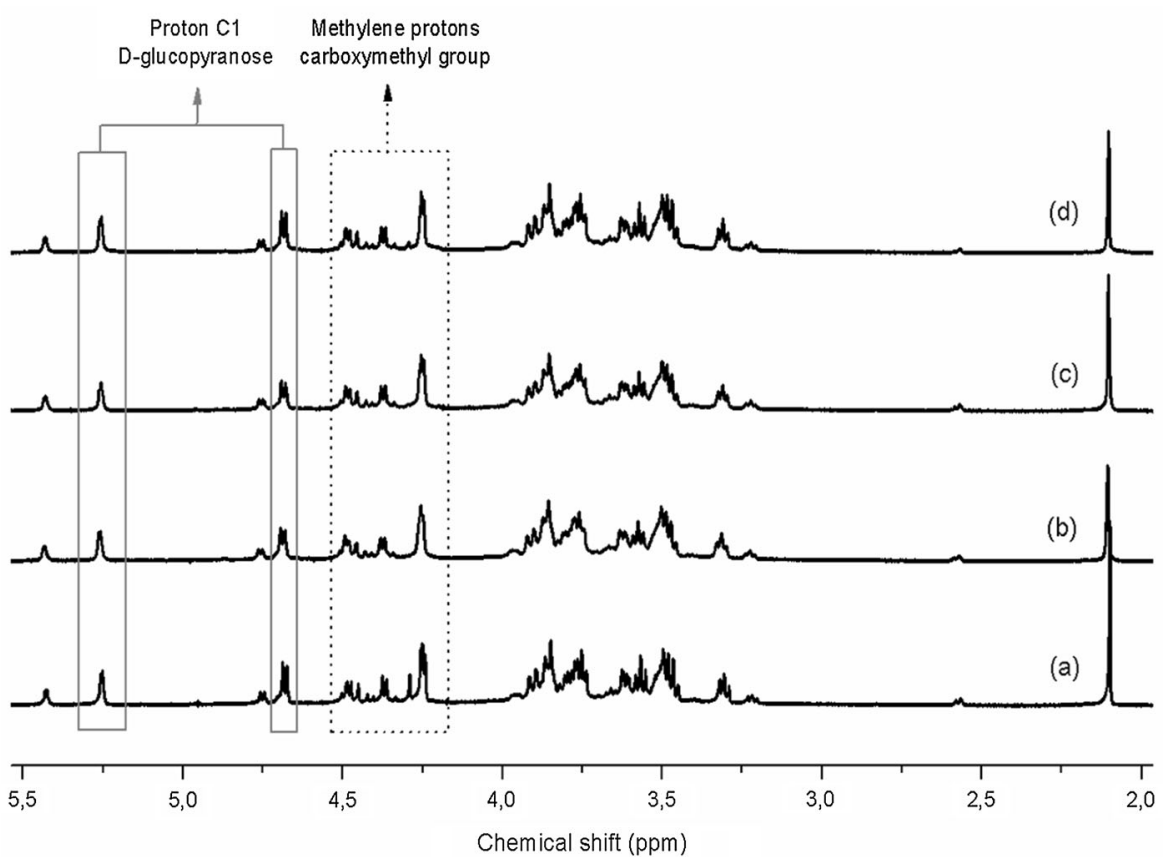

hydrolysis with $\mathrm{H}_{2} \mathrm{SO}_{4}$ present higher degree of sulfonation in relation to the nanocrystals extracted by hydrolysis through the combination of $\mathrm{H}_{2} \mathrm{SO}_{4}$ and $\mathrm{HCl}$. Thus, CBCNC-S-EtOH and CBCNC-S-IPA tend to exhibit a higher amount of sulfate that can react with $\mathrm{NaOH}$, resulting in overestimated values for DSTITR. On the other hand, the CBCNC-S/Cl-EtOH and CBCNC-S/Cl-IPA, where the hydrolysis was carried out through the combined use of acids (promoting a lower degree of sulfonation in the nanocrystals), DSNMR and DS-TITR values presented a good correlation, because the effect of the sulfate group is considerably smaller. In addition, modified BCNC-S/ $\mathrm{Cl}$ has a structure with more free hydroxyls available for substitution than BCNC-S, which results in higher DS values, as observed in Table 2.

\section{Effect of hydrolysis}

The different hydrolysis conditions influenced the DS values (Table 2). Sulfuric acid hydrolysis replaces the hydroxyl group $(-\mathrm{OH})$ with a sulfate group $\left(-\mathrm{OSO}_{3}{ }^{-}\right)$ by esterification on the nanocrystal surface. The presence of hydrochloric acid in the hydrolysis reaction provides hydronium cations with fewer sulfate anions, which reduces the substitution of the hydroxyl group in the nanostructures. Therefore,
BCNC-S presents more sulfate substitution than BCNC-S/Cl. Thus, the nanocrystals from the sulfuric acid and hydrochloric acid mixture have more hydroxyls available to be carboxymethylated, resulting in nanocrystals with a higher DS.

Effect of alcoholic solvents

The type of solvent used in the carboxymethylation reaction also influenced the DS of the BCNCs. IPA yielded a higher DS than ethanol for both CNCs. A more acidic solvent has higher reactivity with sodium. IPA $\left(\mathrm{K}_{\mathrm{a}}=3.2 \times 10^{-17}\right)$ is less acidic than ethanol $\left(\mathrm{K}_{\mathrm{a}}=1.3 \times 10^{-16}\right) \quad$ (McMurry 2013). Thus, IPA shows lower reactivity with $\mathrm{Na}^{+}$ions, letting them react quickly with the free hydroxyl groups present in the cellulose chain to form the alkoxy group, which is more easily attacked by the etherifying agent. Therefore, the efficiency of the replacement by carboxymethylation is highly influenced by the nature of the acid and of the solvent. Pushpamalar et al. (2006) observed similar results for carboxymethylated plant cellulose obtained using different types of solvents. Furthermore, comparison of the DS values of the carboxymethylated nanocrystals and the carboxymethylated plant cellulose (both obtained with the same solvent and under the same reaction 
conditions) indicates that that nanocrystals have larger DS values than the cellulose. This shows that the size of the molecular structure also influences the carboxymethylation process. The nanocrystals have larger surface area compared to its volume unit, making available more hydroxyl groups for the formation of alkoxy followed by the attack of monochloroacetic acid, resulting in a faster rate of substitution. Yeasmin and Mondal (2015) observed similar dependency of the degree of substitution of carboxymethylcellulose on cellulose particle size. However, the carboxymethylation of CNCs tends to provide a more substituted product.

\section{Zeta potential}

Zeta potential values of the CBCNCs can be seen in Table 3 . The carboxymethylated nanocrystals showed negative zeta potential with values close to those of the BCNCs obtained by Vasconcelos et al. (2017) (- 33.6 and $-43.9 \mathrm{mV}$ for BCNC-S and BCNC-S/Cl, respectively). Overall, all the aqueous suspensions of CBCNCs showed good colloidal stability, since they exhibited zeta potential absolute value greater than $30 \mathrm{mV}$ (Mirhosseini et al. 2008).

As stated before, the $\mathrm{CBCNC}-\mathrm{S} / \mathrm{Cl}$ produced with IPA presented a higher DS than the CBCNC-S/Cl produced using EtOH, which also led to higher zeta potential modulus. Similar observation can be made for CBCNC-S samples. This is attributed to the higher amount of negative charges from the insertion of carboxymethyl groups on the surface of the nanocrystals, which can be define as a polyanion. Moreover, the increase of the surface negative charge of the nanocrystals promotes the extension of the polymer chain, in which it improves the interaction with the polycations, thus facilitating the obtaining of the more stable PECs.

\section{Crystal structure}

Figure 5a shows the diffraction spectra of the BC and functionalized nanostructures. XRD pattern of the purified $\mathrm{BC}$ showed the three main characteristic
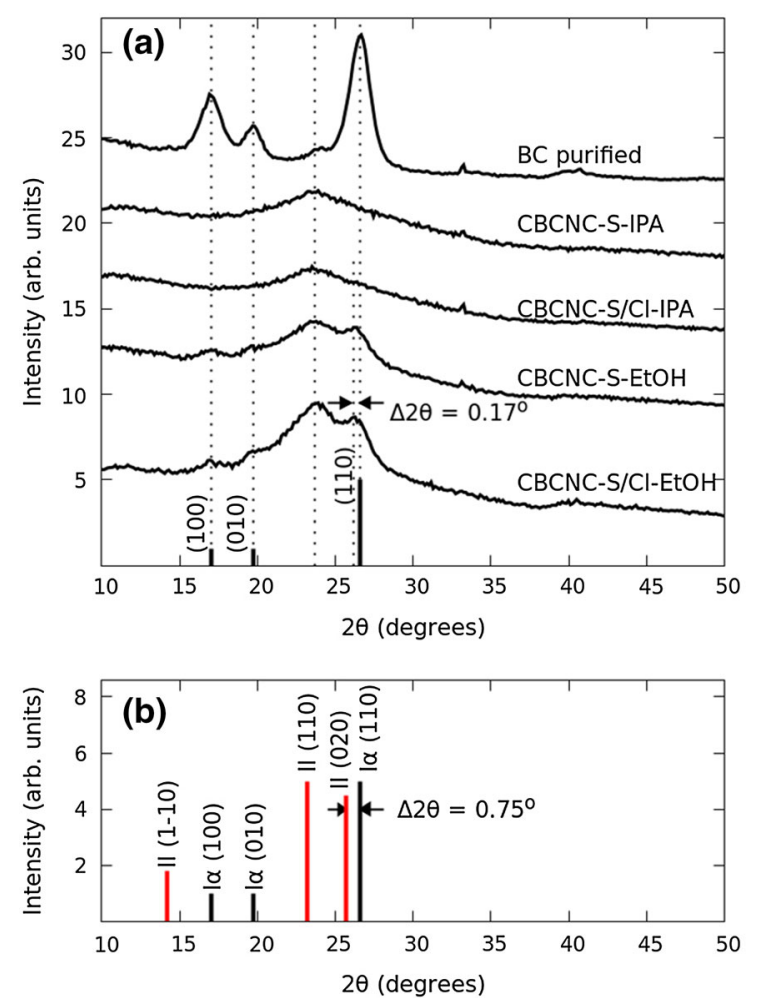

Fig. 5 XRD patterns $\mathbf{a}$ of BC and CBCNCs (functionalized by carboxymethylation); and $\mathbf{b}$ position of diffraction patterns of type $\mathrm{I}_{\alpha}$ cellulose and type II cellulose. These $\mathrm{x}$-ray patters were obtained using $\mathrm{CoK} \alpha$ radiation $(\lambda=1.789 \AA)$

Table 3 Zeta potential, XRD, and TGA results of the CBCNCs

\begin{tabular}{lllll}
\hline Samples & Zeta potential $(\mathrm{mV})$ & XRD & TGA & \\
\cline { 3 - 5 } & & Structure type & Temperature Onset $\left({ }^{\circ} \mathrm{C}\right)$ & Residual mass $(\%)$ \\
\hline Purified BC & n.d. & Cellulose $\mathrm{I}_{\alpha}$ & 333 & 0.6 \\
CBCNC-S-EtOH & $-44 \pm 3.0$ & Cellulose $\mathrm{I}_{\alpha}+$ non-crystalline & 243 & 7.5 \\
CBCNC-S/Cl-EtOH & $-43 \pm 1.5$ & Cellulose $\mathrm{I}_{\alpha}+$ non-crystalline & 251 & 5.6 \\
CBCNC-S-IPA & $-48 \pm 1.8$ & Non-crystalline & 257 & 14 \\
CBCNC-S/Cl-IPA & $-52 \pm 2.5$ & Non-crystalline & 255 & 15.5 \\
\hline
\end{tabular}

n.d. not determined 
peaks of type $I_{\alpha}$ cellulose at $2 \theta \approx 17.0^{\circ}, 19.7^{\circ}$ and $26.6^{\circ}$, which correspond to the crystallographic planes with Miller indices (100), (010) and (110), when a triclinic unit cell with the following parameters is considered; $\mathrm{a}=6.717 \AA, \mathrm{b}=5.962 \AA, \mathrm{c}=10.400 \AA$, $\alpha=118.08, \beta=114.80$ and $\gamma=80.37$ (Nishiyama et al. 2003; Morais et al. 2013; French 2014; Ghasemi et al. 2016). The $I_{\alpha}$ polymorph is most common in BC while $\mathrm{I}_{\beta}$, that has similar peak positions, is most common in plant cellulose (Horii et al. 1987; Sugiyama et al. 1991; Nishiyama et al. 2003). For the crystalline structure of cellulose $\mathrm{I}_{\alpha}$ given by Nishiyama et al. (2003), the (100) and (010) peaks have approximately the same intensity, whereas in Fig. 5a the (100) reflection is considerably stronger. This discrepancy in peak intensity is not uncommon and can be seen in other studies on cellulose, as: Zugenmaier (2008) for plant cellulose; Vasconcelos et al. (2017) for BC/nanowhiskers; Lu and Hsieh (2010) and Morais et al. (2013) for cellulose nanowhiskers. It may be due to some degree of preferred orientation, or the fact that the actual cellulose is not a perfect crystalline structure (structure formed by unit cells totally equal and/or perfectly coupled).

XRD patterns observed for CBCNCs were different when compared to the $\mathrm{BC}$ purified and the nanocrystals studied by Vasconcelos et al. (2017), expressing that the carboxymethylation reaction affected the crystalline integrity arrangement of the material. As observed in the literature, the crystallinity of both cellulose and nanocrystals is altered by the chemical modification process to obtain the cellulose derivatives. This occurs due to the insertion of larger clusters (like the carboxymethyl group) than the hydroxyl, in which it causes a conformational difference, altering the crystalline packaging. Similar result was observed by $\mathrm{Wu}$ et al. (2018b), in which chemically modified cellulose nanocrystals by acetylation, causing a change in their structure. Casaburi et al. (2018) also observed a decrease in crystallinity after carboxymethylation of BC. Furthermore, since these substitutions occur randomly along the polymer chain, it may not be possible to promote enough intermolecular interactions to organize a new crystalline block.

For carboxymethylated nanostructures with ethanol (CBCNC-S-EtOH and CBCNC-S/Cl-EtOH) an allomorphic transformation of cellulose is observed. The diffractograms presented mainly two broad peaks at $2 \theta \approx 23.65^{\circ}$ and $26.43^{\circ}$, which could indicate an allomorphic transformation from type $\mathrm{I}_{\alpha}$ cellulose to type II, where those peaks would correspond to the crystallographic planes (110) and (020) of cellulose type II, respectively (French 2014). For confirmation of the allomorph of type II cellulose, the presence of a diffraction peak at $2 \theta=14.2^{\circ}$ should be evidenced. However, in Fig. 5a this diffraction pattern was not observed, indicating that the nanostructure tends to have unorganized state. Moreover, the angular difference $(\Delta 2 \theta)$ between the crystallographic plane (110) of type $\mathrm{I}_{\alpha}$ and plane (020) of type II can be used to verify the transformation from structure. If the structure of cellulose $\mathrm{I}_{\alpha}$ was transformed into type II cellulose, the theoretical $\Delta 2 \theta$ pattern for the crystallographic plane (110) should be $0.745^{\circ}$ (ranging from $26.6^{\circ}$ to $25.855^{\circ}$ ), as showed in Fig. 5b. However, in the spectra of the samples with ethanol, this $\Delta 2 \theta$ pattern was only $0.170^{\circ}$ (ranging from $26.6^{\circ}$ to $26.43^{\circ}$ ), as showed in Fig. 5a, which still corresponds to a type $\mathrm{I}_{\alpha}$ cellulose structure. This angular shift in the spectra should be attributed to and the presence of the carboxymethyl group in nanostructure that contributes to the increase of the space between crystalline planes (Abraham et al. 2016). In addition, the presence of two weak and broad diffraction peaks at $2 \theta \approx 17.0$ and 19.7 , confirms the presence of type $I_{\alpha}$ cellulose since they correspond to (100) and (010) reflections. The decrease in the intensity and broadening of the peaks are indicative of a partial "amorphization" of structure. Finally, the partial deconstruction of the crystalline arrangement can be observed by the presence of the diffraction peak at $23.5^{\circ}$, that is characteristics of the amorphous cellulose (Zugenmaier 2008; Mukarakate et al. 2016; Hattori and Arai 2016; Leng et al. 2018). Therefore, it is verified that the structure of the samples carboxymethylated with ethanol is formed by a mixture of type $I_{\alpha}$ cellulose and non-crystalline cellulose. For carboxymethylated nanostructures with isopropanol (CBCNC-S-IPA and CBCNC-S/Cl-IPA), a single broad and low intensity peak at $2 \theta \approx 23.5^{\circ}$ characterizes a structure tendency in becoming noncrystalline.

It could be argued that increasing of substitutes in the crystalline structure in a random/heterogeneous form in the glucopyranose ring tends to distort the organization of the atoms and the fit between the unit cells, generating a disorganized structure with poor crystallinity. Further, as noted in the literature, a highly substituted crystal structure tends to exhibit 
additional XRD peaks depending on the size of the substituents of the hydroxyl groups of cellulose (indicating the formation of new crystallographic planes) (Abraham et al. 2016). The change of cellulose from type $I_{\alpha}$ to non-crystalline, results in a more flexible structure, capable of interlacing and stabilizing with other polymers of opposite charge, favoring the complexation and formation of the PECs.

On the other hand, although the literature shows that the degree of substitution influences the crystalline structure of the cellulose, our study did not verify a direct correlation between crystallinity and the values of DS. Moreover, as the effect of hydrolysis on the extraction of BCNCs influenced the degree of substitution, the types of nanocrystals used in carboxymethylation did not present alterations in the XRD patterns. It is known that the nanostructures obtained only with sulfuric acid have a high density of sulphate group on its surface and, consequently, a smaller number of hydroxyls available to react with $\mathrm{NaOH}-$ - Na-cellulose" - in the alkalization step. In addition, occur steric hindrance in the substitution of the remaining hydroxyls by the carboxymethyl group, resulting in nanocrystals with lower DS values. The nanostructures obtained by the mixture of sulfuric and hydrochloric acid have more hydroxyls available, forming more "Na-cellulose", in which it allows the occurrence of allomorphic transformation of cellulose and favors the substitution in the structure, resulting in nanocrystals with higher DS values. Nevertheless, any valid consideration can be made about the use of $\mathrm{BCNC}-\mathrm{S}$ and BCNC-S/Cl.

Despite the fact that no direct correlation can be obtained between DS and crystallinity, it is possible to observe that the effect of the alcoholic solvent used in the functionalization of the nanocrystals affected the crystalline structure of the cellulose, determining its transformation partial (in the case of ethanol) or total (in the case of isopropanol) in a non-crystalline material. This alomorphism that occurs in the nanostructures is related to the alkalization step (also reported as mercerization) in the $\mathrm{CMC}$ production process. As reported in the literature, $\mathrm{NaOH}$ promotes the transition from type $\mathrm{I}_{\alpha}$ cellulose to type II cellulose (more stable crystalline form), and this process is irreversible. However, the concentration of the alkali solution may be considerably important in determining the structure of the CMC. High concentrations (as in our study) promote a complete transformation from crystalline cellulose to Na-cellulose, in which it changes its skeletal structure (Ambjörnsson et al. 2013). As already discussed above, the more acidic alcoholic solvent has higher affinity for the sodium ion (item 3.4). Thus, the use of ethanol in carboxymethylation will compete in the formation of Na-cellulose, reducing its interaction with the structure. On the other hand, isopropanol has a lower affinity for $\mathrm{Na}^{+}$, leaving the ions free to react with the cellulose, forming more Na-cellulose and disorganizing the structure of the material.

The crystallite sizes (CS) for purified BC were very similar: $9.3,9.4$ and $9.5 \mathrm{~nm}$, in the direction of the three main peaks (100), (010), and (110), respectively, forming an isotropic crystallite. The percentage of crystallites present in the structure of $\mathrm{BC}$ is represented by the index of crystallinity (CrI) and was $81 \%$. For the carboxymethylated nanostructures prepared with isopropanol, the values of CS could not be calculated because the structure is non-crystalline while $\mathrm{CrI}=0 \%$ (French and Cintrón, 2013). For the carboxymethylated nanostructures prepared with ethanol, the severe peak overlap prevented us of obtaining meaningful values for DS and CrI. Suffice to say that there is some degree of crystallinity due to the presence of type $\mathrm{I}_{\alpha}$.

\section{Thermal analysis (TGA/DSC)}

Thermogravimetric (TG) curves and their respective derivative thermogravimetric (DTG) curves of CBCNCs and purified BC are shown in Fig. 6. The curves from the samples have three thermal mass loss events. The first one, around $50-150{ }^{\circ} \mathrm{C}$, is attributed to the evaporation of residual water from the drying process. The difference between the mass losses of the $\mathrm{CBCNC}$ and the $\mathrm{BC}$ is attributed to the increase in the hydrophilic nature of cellulose nanocrystals after carboxymethylation, which leads to higher moisture content in the functionalized nanocrystals. In fact, similar results were reported by Varma et al. (2016). The second event, occurring in the range of 200-400 ${ }^{\circ} \mathrm{C}$, corresponds to cellulose degradation, and is associated with a high mass loss observed in the cellulosic material. This high mass loss is due to a series of reactions such as: dehydration, depolymerisation, and decomposition, characterizing its onset temperature $\left(\mathrm{T}_{\text {Onset }}\right)$. Table 3 shows the $\mathrm{T}_{\text {Onset }}$ values for all $\mathrm{CBCNCs}$ obtained using $\mathrm{EtOH}$ and IPA. The 
Fig. 6 a TG and b DTG curves of purified $\mathrm{BC}$ and BCNCs functionalized by carboxymethylation in an alcoholic solvent (EtOH and IPA)
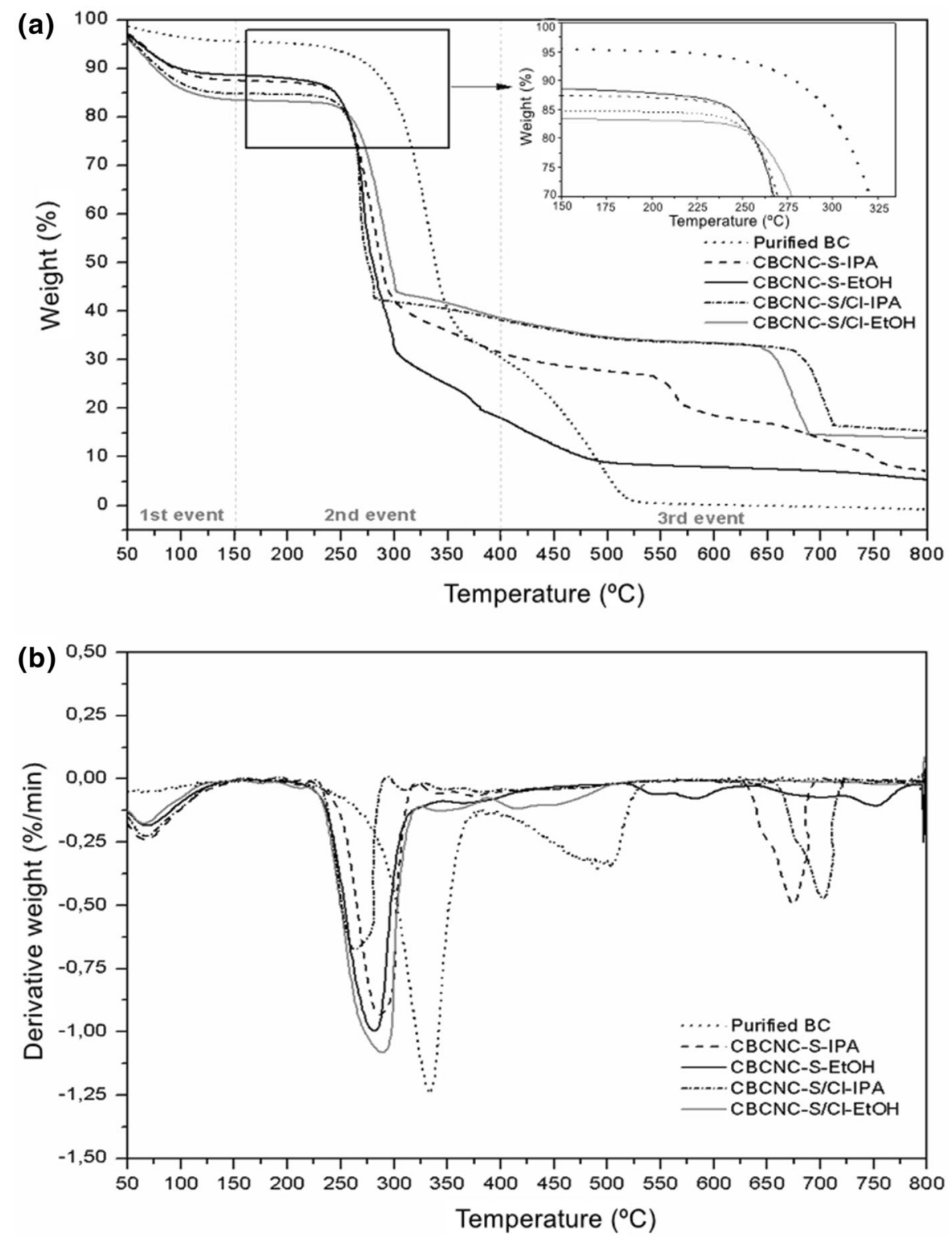

type of solvent used in the carboxymethylation reaction did not change the $\mathrm{T}_{\text {Onset }}$ values considerably. The difference in $\mathrm{T}_{\text {Onset }}$ values between $\mathrm{CBCNC}$ and purified $\mathrm{BC}$ could be due to the higher crystallinity of $\mathrm{BC}$ film and the lower amount of intramolecular hydrogen bonds in carboxymethylated nanocrystals. In addition, due to their conformation differences, cellulose I has a much higher modulus (140 GPa) than cellulose II $(90 \mathrm{GPa})$ than amorphous cellulose $(<20$ $\mathrm{GPa}$ ), as reported by Wan et al. (2017). The third thermal event, which extends from 450 to $800{ }^{\circ} \mathrm{C}$, is related to oxidation and breakdown of carbonaceous residues and organic salts (e.g. sodium acetate, products formed in depolymerisation of carboxymethylcellulose), yielding gaseous products of low molar mass.

From the thermal analysis, one may observe a degradation profile similar to the one presented by the CNCs (not chemically derivatized) studied by Vasconcelos et al. (2017). However, it is noted that CBCNC-S-IPA and CBCNC-S-EtOH showed an increase in the $\mathrm{T}_{\text {Onset }}$ value $\left(34{ }^{\circ} \mathrm{C}\right.$ and $20{ }^{\circ} \mathrm{C}$, respectively) compared to non-functionalized $\mathrm{BCNCs}$ obtained by Vasconcelos et al., (2017) $\left(223{ }^{\circ} \mathrm{C}\right.$ for 
BCNC-S). This increase can be due to new interactions and/or chemical bonds formed and/or the increase in molar mass (carboxymethyl group has a higher atomic volume/molar mass than the sulfate group). In addition, the substitution reaction may have eliminated some sulfate groups on the surface of nanocrystals. The presence of these groups is related to decreases in the activation energy during thermal degradation of cellulose nanocrystals that were obtained by hydrolysis with sulfuric acid. It is known that chemical modification on the surface of cellulose nanocrystals could change the thermogravimetric behavior of the material (Fukuzumi et al. 2008;

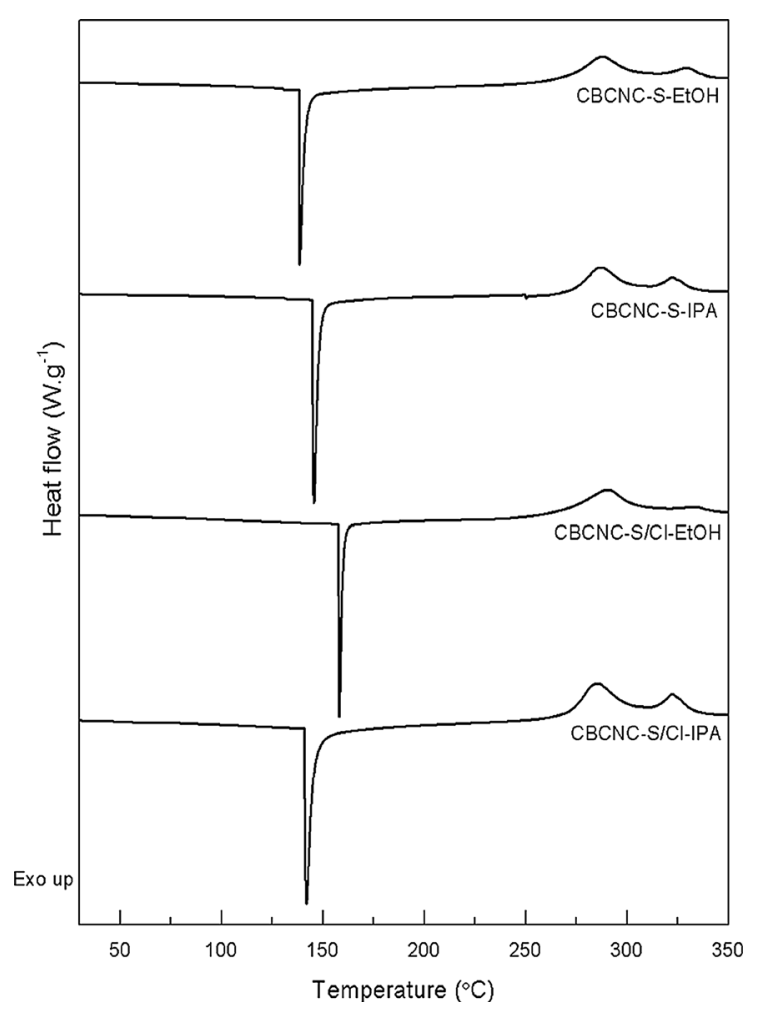

Fig. 7 DSC curves of BCNCs functionalized by carboxymethylation in an alcoholic solvent (EtOH and IPA)
Petersson et al. 2007; Ge and Li 2013). However, in the case of CBCNC-S/Cl-IPA and CBCNC-S/Cl$\mathrm{EtOH}$ the degradation temperatures did not change significantly after the carboxymethylation reaction when compared with the nanocrystals studied by Vasconcelos et al. (2017) $\left(263{ }^{\circ} \mathrm{C}\right.$ for BCNC-S/Cl).

Comparing the profiles of the TG curves, the residual mass from carboxymethylated nanostructures showed a marked increase (see Table 3). This high percentage of ashes comes from the decomposition of the sodium salt of carboxymethylcellulose. In addition, the higher the DS value observed in the samples, the greater the percentage of ash produced.

Figure 7 shows DSC thermograms of CBCNCs. It can be observed the presence of three peaks: the first peak being endothermic, and the second and third peaks being exothermic. Table 4 shows the temperature and enthalpy values observed in each event. The endothermic peaks occurred in the range of $130-160{ }^{\circ} \mathrm{C}$, which correspond to the crystalline melting temperature $\left(\mathrm{T}_{m}\right)$ of the polymer. A similar result was reported by Varma et al. (2016), who observed endothermic transitions around $140{ }^{\circ} \mathrm{C}$ for carboxymethylated orange pulp cellulose. According to Vasconcelos et al. (2017), $\mathrm{T}_{m}$ values for BCNCs ranged from 140 to $195{ }^{\circ} \mathrm{C}$. Therefore, when compared with the $\mathrm{T}_{m}$ values for the CBCNCs, it can be observed that there was no change after the chemical modification of the nanocrystals. In the DSC curve, the glass transition $\left(\mathrm{T}_{g}\right)$ was not observed due the presence of intermolecular bonds in the cellulose chain that makes rotational movement of the chemical bonds present in the monomers very difficult, resulting in the decomposition of the cellulosic material before the event.

The second peak presented an exothermic character and occurred around $273{ }^{\circ} \mathrm{C}$. This peak is related to initial degradation temperature $\left(\mathrm{T}_{d}\right)$ of the carboxymethylated cellulosic material, which includes dehydration, decarboxylation, and decarbonylation.
Table 4 Temperature and enthalpy values of the BCNCs modified via carboxymethylation reaction

\begin{tabular}{|c|c|c|c|c|c|c|}
\hline \multirow[t]{2}{*}{ Samples } & \multicolumn{2}{|c|}{ 1st peak endothermic } & \multicolumn{2}{|c|}{ 2nd peak exothermic } & \multicolumn{2}{|c|}{ 3rd peak exothermic } \\
\hline & $\mathrm{T}_{m}\left({ }^{\circ} \mathrm{C}\right)$ & $\Delta \mathrm{H}_{m}\left(\mathrm{~J} \mathrm{~g}^{-1}\right)$ & $\mathrm{T}_{d}\left({ }^{\circ} \mathrm{C}\right)$ & $\Delta \mathrm{H}_{d}\left(\mathrm{~J} \mathrm{~g}^{-1}\right)$ & $\mathrm{T}_{f}$ & $\Delta \mathrm{H}_{f}\left(\mathrm{~J} \mathrm{~g}^{-1}\right)$ \\
\hline CBCNC-S-EtOH & 138 & 141 & 273 & 97 & 319 & 25 \\
\hline CBCNC-S/Cl-EtOH & 157 & 90 & 272 & 87 & 323 & 9 \\
\hline CBCNC-S-IPA & 144 & 190 & 274 & 128 & 315 & 38 \\
\hline CBCNC-S/Cl-IPA & 141 & 141 & 273 & 147 & 323 & 37 \\
\hline
\end{tabular}


Before carboxymethylation

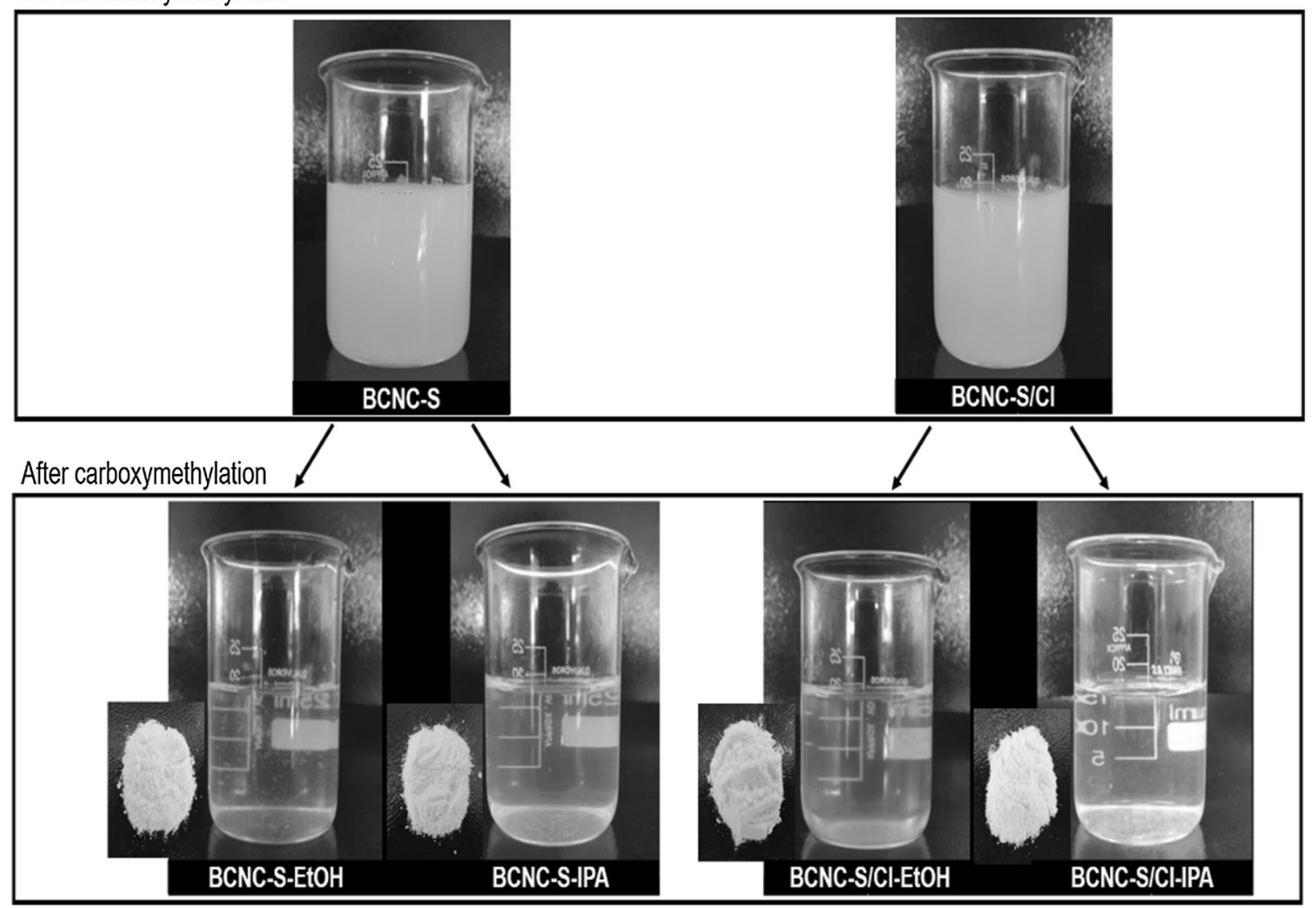

Fig. 8 Images of aqueous suspensions of nanocrystals before and after carboxymethylation with the respective sodium salts of $\mathrm{CBCNCs}$

The difference between $\mathrm{T}_{\text {Onset }}$ (observed by TGA) and $\mathrm{T}_{d}$ (obtained by DSC) values shall be attributed to different $\left(\mathrm{N}_{2}\right.$ and synthetic air) gases used in the analyses. The peak area provides the enthalpy variation values of the carboxymethylcellulose decomposition reaction $\left(\Delta \mathrm{H}_{d}\right)$. The $\Delta \mathrm{H}_{d}$ values obtained for CBCNC-S-IPA and CBCNC-S/Cl-IPA were higher than those for the CBCNC-S-EtOH and CBCNC-S/ClEtOH samples. This may be due to the more homogeneous substitution of the nanocrystalline cellulose samples obtained with IPA, probably leading to more stable intermolecular interactions.

Finally, the third exothermic peak was observed around $320{ }^{\circ} \mathrm{C}$ and corresponds to initial formation temperature $\left(\mathrm{T}_{f}\right)$ of levoglucosan, which is the structure resulting from the degradation process of anhydrocellulose through the elimination reaction of intramolecular water (transglycosylation). CBCNCS-IPA and CBCNC-S/Cl-IPA showed enthalpy variation values of the levoglucosan formation reaction $\left(\Delta \mathrm{H}_{f}\right)$ higher than those of carboxymethylated nanocrystals produced using ethanol, due to the formation of more stable anhydrocellulose. This result can be correlated with the residual mass observed in the TG curves (see Table 3), showing that the percentage of ashes formed was derived from the levoglucosan degradation and formation of sodium salt.

\section{Morphology}

Figure 8 shows the aqueous suspensions of nanocrystals before (BCNC-S and BCNC-S/Cl) and after carboxymethylation reaction (CBCNC-S-EtOH, CBCNC-S-IPA, CBCNC-S/Cl-EtOH and CBCNC-S/ Cl-IPA), in which presented in the form of a sodium salt, with white coloration. Comparing the images, it can be observed that the type of acid used in the 


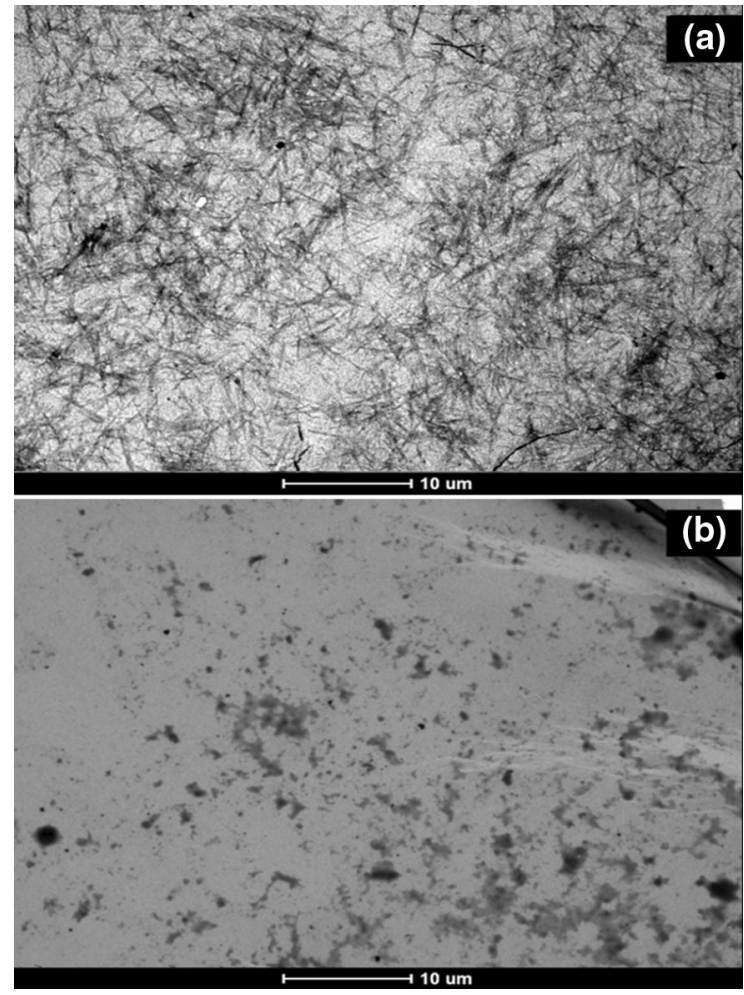

Fig. 9 TEM micrographs of a BCNC-S/Cl and b CBCNC-S/ Cl-IPA

extraction of BCNCs and the type of alcoholic solvent used in the carboxymethylation reaction did not influence the visual aspects of the salts. However, a change in color between the solutions in water can be observed. After the functionalization, the appearance of the suspension of BCNCs changed from opaque to translucent, due to the presence of the substituent group, which is more easily solvated by water molecules, suggesting solubility in aqueous media of the nanocrystals. No distinction in the visual aspect of the modified nanocrystals solutions was observed for the two different solvents and the DS values.

TEM analysis of nanocrystals that presented the highest DS value (CBCNC-S/Cl-IPA) was performed to evaluate their structures before and after carboxymethylation. Figure $9 \mathrm{a}, \mathrm{b}$ shows the micrographs of BCNC-S/Cl (non-functionalized) and CBCNC-S/ Cl-IPA (functionalized), respectively. The non-functionalized nanocrystals have needle-shaped structures with a length $(L)$ ranging from 300 to $760 \mathrm{~nm}$ $(\bar{L}=644.2 \pm 95.2 \mathrm{~nm})$ and a width $(D)$ ranging from 23 to $70 \mathrm{~nm}(\bar{D}=48.8 \pm 19.7 \mathrm{~nm})$, corresponding to an aspect ratio $(L / D)$ of $17.7 \pm 7.5$. These results agree with those reported by Vasconcelos et al. 2017. However, the functionalized nanocrystals produced using IPA lost the needle shape, acquiring an amorphous appearance, which can result from the breaking of the hydrogen bonds between the cellulose chains, due to the substitution of hydroxyl $(\mathrm{OH})$ by the carboxymethyl group $\left(-\mathrm{CH}_{2} \mathrm{COO}^{-}\right)$which is more voluminous. These results are consistent with those reported in the literature for plant cellulose (Yeasmin and Mondal 2015). Furthermore, it can be observed that the CBCNC-S/Cl-IPA structure changes, forming a new morphology. According to Haleem et al. (2014), the structural and morphological modification of polysaccharide chains is due to the alkaline environment during the carboxymethylation reaction.

\section{Preliminary characterization of PECs}

According to the results obtained in this work, the CBCNC-S/Cl-IPA was selected because it presented the highest value of DS and, consequently, solvation, solubility and high density of negative surface charges when in aqueous solution. Thus, it was used as a polyanion to obtain PECs, along with chitosan, which is in the polycation. The obtained nanoparticulate system was, preliminarily, characterized by zeta potential and particle size and results are shown in Table 5 .

The zeta potential of the aqueous suspension was measured to verify the surface charges of the nanoparticles, in relation to charge ratios. For sample with the same charge molar ratio $\left(\mathrm{q}^{+} / \mathrm{q}^{-}=1\right)$, the particles had a slightly negative but tended to zero potential value. This shows that occurred an equal amount of positive charge existent in chitosan $\left(-\mathrm{NH}_{3}{ }^{+}\right)$with the amount of negative charge of CBCNC-S/Cl-IPA $\left(-\mathrm{COO}^{-}\right)$, generating charge-free surface nanoparticles with low stability in water. For the charge ratio of $0.5 \mathrm{(q}^{+} /$ $\mathrm{q}^{-}<1$ ), where there is a negative charge excess, the Zeta potential showed negative values, indicating that the particle surface is covered with modified nanocrystals, with free carboxylate anion. On the other hand, the charge ratio of $5\left(\mathrm{q}^{+} / \mathrm{q}^{-}>1\right)$, where there is a positive charge excess, showed positive Zeta potential values, indicating that the surface of the nanoparticle is covered with chitosan and has free protonated amine group. The aqueous suspensions obtained from the complexes with charge ratios of 0.5 and 5 showed high 
Table 5 Zeta potential, mean diameter (D), and polydispersity index (PDI) for the polyelectrolyte complexes of Chitosan in CBCNC-S/Cl-IPA and CBCNC-S/Cl-IPA in Chitosan at the concentration of $0.1 \%(\mathrm{w} / \mathrm{v})$

\begin{tabular}{|c|c|c|c|c|c|c|}
\hline \multirow[t]{3}{*}{ Charge ratio $\left(\mathrm{q}^{+} / \mathrm{q}^{-}\right)$} & \multicolumn{6}{|c|}{ Order of addition of polyelectrolytes } \\
\hline & \multicolumn{3}{|c|}{ Chitosan in CBCNC-S/Cl-IPA } & \multicolumn{3}{|c|}{ CBCNC-S/Cl-IPA in Chitosan } \\
\hline & Zeta potential $(\mathrm{mV})$ & $\overline{\mathrm{D}}(\mathrm{nm})$ & PDI & Zeta potential $(\mathrm{mV})$ & $\overline{\mathrm{D}}(\mathrm{nm})$ & PDI \\
\hline 0.5 & $-24 \pm 2.9$ & $391 \pm 7.8$ & $0.5 \pm 0.02$ & $-32 \pm 1.2$ & $514 \pm 12.3$ & $0.5 \pm 0.05$ \\
\hline 1 & $-0.3 \pm 0.3$ & $386 \pm 6.9$ & $0.3 \pm 0.04$ & $-0.5 \pm 1.4$ & $588 \pm 20.2$ & $0.3 \pm 0.07$ \\
\hline 5 & $+37 \pm 1.0$ & $276 \pm 15.8$ & $0.3 \pm 0.02$ & $+39 \pm 1.6$ & $355 \pm 15.7$ & $0.3 \pm 0.03$ \\
\hline
\end{tabular}

surface charge density (negative and positive, respectively) thus presenting good stability. Regarding the order of addition of the electrolytic solutions, it can be observed that, practically, there were no significant changes in the Zeta potential values.

The results observed are consistent with those of the literature. Boddohi et al. (2009) synthesized nanoparticles by electrolytic complexation of chitosan $(+) /$ heparin (-) and chitosan (+)/hyaluronic acid (-) in different charge ratios and observed that ratios larger than 1 (higher molar amount of polycation), the potential values were positive and at loading ratios less than 1 (higher molar amount of the polyanion), zeta potential values were negative. Campelo et al. (2016) developed films from PECs (sulfonated chitosan and carrageenan) with anti-thrombogenic and anti-calcifying properties. According to the referred study, for films to exhibit these properties, their surface must be negatively charged, preventing the adsorption of proteins from blood plasma, lipids, calcium, platelets, leukocytes and erythrocytes. The authors applied these films as coating of cardiac biomaterials, providing an improvement in the biocompatibility of the implanted material, thus guaranteeing long-term success.

The particle size (average diameter, $\overline{\mathrm{D}}$ ) of nanoparticles tend to decrease with the increase in the amount of positive charges. As can be observed, the smaller particle diameter was obtained by $\mathrm{q}^{+} / \mathrm{q}^{-}=5$, where the molar amount of chitosan is higher. The difference between the values of $\overline{\mathrm{D}}$ with respect to order of addition of the polyelectrolytes is based on the difference in molar mass between polyions. Since chitosan presents a higher molar mass and a high density of positive charge, tends to interact more strongly with the negative polyelectrolyte (CBCNC-S/ Cl-IPA) promoting the contraction of the complexes and, consequently, a decrease in its diameter, as reported by Schatz et al. (2004). Another factor that could affect the diameter of the particles formed by polyelectrolytes-which it is directly related to its size - is the flexibility of the polymer chain. The CBCNC-S/Cl-IPA polyanion exhibits low molar mass because it is a product obtained from a reaction of acid hydrolysis. In this way, BCNC have a shorter chain than the starting cellulosic material and a reduced flexibility, which makes it difficult to interact with other polycations of high molar mass, such as chitosan. In the regions where the modified nanocrystals interact with the chitosan, there is a stiffening of the chitosan polymer chain. Thus, complexes formed from CBCNC-S/Cl-IPA in chitosan exhibited particles with larger diameters than the complexes obtained from chitosan in CBCNC-S/Cl-IPA.

The polydispersity index (PDI) is an important parameter to be evaluated because it determines the variety of particle size present in the aqueous solution. It can be observed that the smaller the diameter of the particles the lower the PDI values, showing that the complexes formed are more homogeneous in relation to the size. Similar result was obtained by Schatz et al. (2004), where they obtained complexes from chitosan and dextran sulfate and observed that the smaller the particle size the more discrete was the decrease in the polydispersity of the samples. The profile of the particle distribution of the polyelectrolyte nanocomplexes obtained in this work is found in the supplementary materials.

\section{Conclusions}

This study evaluates the acid hydrolysis process and the use of EtOH and IPA in the chemical modification of BCNCs by carboxymethylation. The use of IPA as a 
solvent in the reaction provided a higher reactivity, and a higher DS. The nanocrystals obtained by hydrolysis with a combination of sulfuric and hydrochloric acids (BCNC-S/Cl) showed more degree of substitution compared with those obtained by hydrolysis with sulfuric acid only (BCNC-S). The chemical modification did not alter the thermal stability of CBCNCs and promoted an improvement in the hydrophilic character, making them solvable in all DS values obtained. Moreover, the increase in negative charge density (high zeta potential), a change in the crystal structure (transformation cellulose type $\mathrm{I}_{\alpha}$ for amorphous), allowed its use as a polyanion in the preparation of polyelectrolyte complex. The PECs synthesized from bacterial carboxymethyl cellulose nanocrystals with chitosan showed variable sizes (276-588 nm) with different surface charges. In our future research, we will evaluate in more details the use of CBCNC for the development of other products, such as the coating of biomaterials in contact with the blood (such as stents), providing surface with antithrombogenic and anti-calcification properties.

Acknowledgments The authors wish to acknowledge the financial support provided by the Coordination for the Improvement of Higher Education Personnel (CAPES, Brazil), the National Council of Technological and Scientific Development (CNPq, Brazil), the Foundation for Science and Technology (FCT, Portugal), the Institute for Biotechnology and Bioengineering (IBB, University of Minho, Portugal), Instituto Nacional de Ciência e Tecnologia em Materiais Complexos Funcionais (INOMAT, Brazil), and the Embrapa Agroindústria Tropical. This research was also supported by the international collaboration program FCT/CAPES (No. 99999.008530/2014-09). The authors would like to thank the Fundação Oswaldo Cruz (FIOCRUZ - Instituto Aggeu Magalhães) and the Laboratório de Raios-X (LRX - UFC) for supporting the analysis of TEM and XRD, respectively.

\section{References}

Abraham E, Kam D, Nevo Y, Slattegard R, Rivkin A, Lapidot S, Shoseyov O (2016) Highly modified cellulose nanocrystals and formation of epoxy-nanocrystalline cellulose (CNC) nanocomposites. ACS Appl Mater Interfaces 8(41):28086-28095. https://doi.org/10.1021/acsami. $6 \mathrm{~b} 09852$

Ambjörnsson HA, Schenzel K, Germgard U (2013) Carboxymethyl cellulose produced at different mercerization conditions and characterized by NIR FT Raman spectroscopy in combination with multivariate analytical methods. BioResources 8(2):1918-1932
ASTM: D1439-15 (2015) Standard test methods for sodium carboxymethylcellulose. ASTM International, West Conshohocken. https://doi.org/10.1520/D1439-15

Bigucci F, Abruzzo A, Vitali B, Saladini B, Cerchiara T, Gallucci MC, Luppi B (2015) Vaginal inserts based on chitosan and carboxymethylcellulose complexes for local delivery of chlorhexidine: preparation, characterization and antimicrobial activity. Int J Pharm 478:456-463. https://doi.org/10.1016/j.ijpharm.2014.12.008

Boddohi S, Moore N, Johnson PA, Kipper MJ (2009) Polysaccharide-Based Polyelectrolyte Complex Nanoparticles from Chitosan, Heparin, and Hyaluronan. Biomacromolecules 10(6):1402-1409. https://doi.org/10.1021/ bm801513e

Campelo CS, Lima LD, Rebêlo LM, Mantovani D, Beppu MM, Vieira RS (2016) In vitro evaluation of anti-calcification and anti-coagulation on sulfonated chitosan and carrageenan surfaces. Mater Sci Eng C Mater 59:241-248. https://doi.org/10.1016/j.msec.2015.10.020

Candido RG, Gonçalves AR (2016) Synthesis of cellulose acetate and carboxymethylcellulose from sugarcane straw. Carbohydr Polym 152:679-686. https://doi.org/10.1016/j. carbpol.2016.07.071

Casaburi A, Montoya Rojo Ú, Cerrutti P, Vázquez A, Foresti ML (2018) Carboxymethyl cellulose with tailored degree of substitution obtained from bacterial cellulose. Food Hydrocoll 75:147-156. https://doi.org/10.1016/j.foodhyd. 2017.09.002

Cha R, He ZB, Ni YH (2012) Preparation and characterization of thermal $/ \mathrm{pH}$-sensitive hydrogel from carboxylated nanocrystalline cellulose. Carbohydr Polym 88:713-718. https://doi.org/10.1016/j.carbpol.2012.01.026

Chang W, Chen H (2016) Physical properties of bacterial cellulose composites for wound dressings. Food Hydrocoll 53:75-83. https://doi.org/10.1016/j.foodhyd.2014.12.009

Charreau H, Foresti ML, Vázquez A (2013) Nanocellulose patents trends: a comprehensive review on patents on cellulose nanocrystals, microfibrillated, and bacterial cellulose. Recent Pat Nanotechnol 7:56-80. https://doi.org/10. 2174/187221013804484854

Chawla PR, Bajaj IB, Survase SA, Singhal RS (2009) Microbial cellulose: fermentative production and applications. Food Technol Biotechnol 47:107-124

Coseri S, Biliuta G, Simionescu BC, Stana-Kleinschek K, Ribitsch V, Harabagiu V (2013) Oxidized cellulose-survey of the most recent achievements. Carbohydr Polym 93:207-215. https://doi.org/10.1016/j.carbpol.2012.03. 086

Das AM, Ali AA, Hazarika MP (2014) Synthesis and characterization of cellulose acetate from rice husk: eco-friendly condition. Carbohydr Polym 112:342-349. https://doi.org/ 10.1016/j.carbpol.2014.06.006

Degen T, Sadki M, Bron E, König U, Nénert G (2014) The highscore suite. Powder Diffr 29:13-18

Dufresne A (2012) Nanocellulose: from nature to high performance tailored materials (chapter 3), 1st edn. Walter de Gruyter, Boston

Dufresne A (2017) Cellulose nanomaterial reinforced polymer nanocomposites. Curr Opin Colloid Interface Sci 29:1-8. https://doi.org/10.1016/j.cocis.2017.01.004 
Elomaa M, Asplund T, Soininen P, Laatikainen R, Peltonen S, Hyvarinen S, Urtti A (2004) Determination of the degree of substitution of acetylated starch by hydrolysis, H-1 NMR and TGA/IR. Carbohydr Polym 57:261-267. https://doi. org/10.1016/j.carbpol.2004.05.003

Ferreira FV, Mariano M, Rabelo SC, Gouveia RF, Lona LMF (2018) Isolation and surface modification of cellulose nanocrystals from sugarcane bagasse waste: from a microto a nano-scale view. Appl Surf Sci 436:1113-1122. https://doi.org/10.1016/j.apsusc.2017.12.137

French AD (2014) Idealized powder diffraction patterns for cellulose polymorphs. Cellulose 21(2):885-896. https:// doi.org/10.1007/s10570-013-0030-4

French AD, Cintrón MS (2013) Cellulose polymorphy, crystallite size, and the Segal crystallinity index. Cellulose 20(1):583-588. https://doi.org/10.1007/s10570-012-9833$\mathrm{y}$

Fukuzumi H, Saito T, Iwata T, Kumamoto Y, Isogai A (2008) Transparent and high gas barrier films of cellulose nanofibers prepared by TEMPO-mediated oxidation. Biomacromol 10:162-165. https://doi.org/10.1021/ bm801065u

Gama M, Gatenholm P, Klemm D (eds) (2012) Bacterial nanocellulose: a sophisticated multifunctional material (chapter 2). CRC Press, Boca Raton

Ge Y, Li Z (2013) Preparation and evaluation of sodium carboxymethylcellulose from sugarcane bagasse for application in coal-water slurry. J Macromol Sci A 50(7):757-762. https://doi.org/10.1080/10601325.2013.792646

Ghasemi S, Behrooz R, Ghasemi I (2016) Extraction and characterization of nanocellulose structures from linter dissolving pulp using ultrafine grinder. J Nanosci Nanotechnol 16(6):5791-5797. https://doi.org/10.1166/jnn. 2016.12416

Grishkewich N, Mohammed N, Tang J, Tam KC (2017) Recent advances in the application of cellulose nanocrystals. Curr Opin Colloid Interface Sci 29:32-45. https://doi.org/10. 1016/j.cocis.2017.01.005

Gromovykh TI, Sadykova VS, Lutcenko SV, Dmitrenok AS, Feldman NB, Danilchuk TN, Kashirin VV (2017) Bacterial cellulose synthesized by Gluconacetobacter hansenii for medical applications. Appl Biochem Microbiol 53:60-67. https://doi.org/10.1134/S0003683817010094

Gu J, Catchmark JM, Kaiser EQ, Archibald DD (2013) Quantification of cellulose nanowhiskers sulfate esterification levels. Carbohydr Polym 92:1809-1816. https://doi.org/ 10.1016/j.carbpol.2012.10.078

Guo J, Catchmark JM (2012) Surface area and porosity of acid hydrolyzed cellulose nanowhiskers and cellulose produced by Gluconacetobacter xylinus. Carbohydr Polym 87:1026-1037. https://doi.org/10.1016/j.carbpol.2011.07. 060

Habibi Y (2014) Key advances in the chemical modification of nanocelluloses. Chem Soc Rev 43:1519-1542. https://doi. org/10.1039/C3CS60380F

Haleem N, Arshad M, Shahid M, Tahir MA (2014) Synthesis of carboxymethyl cellulose from waste of cotton ginning industry. Carbohydr Polym 113:249-255. https://doi.org/ 10.1016/j.carbpol.2014.07.023

Hattori K, Arai A (2016) Preparation and hydrolysis of waterstable amorphous cellulose. ACS Sustain Chem Eng
4(3):1180-1186. https://doi.org/10.1021/acssuschemeng. $5 \mathrm{~b} 01247$

Ho FF, Klosiewicz DW (1980) Proton nuclear magnetic resonance spectrometry for determination of substituents and their distribution in carboxymethylcellulose. Anal Chem 52:913-916. https://doi.org/10.1021/ac50056a032

Horii F, Hirai A, Kitamaru R (1987) CP/MAS carbon-13 NMR spectra of the crystalline components of native celluloses. Macromolecules 20(9):2117-2120. https://doi.org/10. 1021/ma00175a012

Ibrahim AA, Adel AM, El-Wahab ZH, Al-Shemy MT (2011) Utilization of carboxymethyl cellulose based on bean hulls as chelating agent synthesis, characterization and biological activity. Carbohydr Polym 83:94-115. https://doi.org/ 10.1016/j.carbpol.2010.07.026

Kian LK, Jawaid M, Ariffin H, Karim Z (2018) Isolation and characterization of nanocrystalline cellulose from rosellederived microcrystalline cellulose. Int J Biol Macromol 114:54-63. https://doi.org/10.1016/j.ijbiomac.2018.03. 065

Krystynowicz A, Czaja W, Wiktorowska-Jezierska A, Gonçalves-Miskiewicz M, Turkiewicz M, Bielecki S (2002) Factors affecting the yield and properties of bacterial cellulose. J Ind Microbiol Biotechnol 29:189-195. https://doi. org/10.1038/sj.jim.7000303

Lankalapalli S, Kolapalli VRM (2009) Polyelectrolyte complexes: a review of their applicability in drug delivery technology. Indian J Pharm Sci 71:481-487. https://doi. org/10.4103/0250-474X.58165

Leng I, Zhang Y, Peng Y, Gong X, Mao M, Li X, Yu Y (2018) In situ structural changes of crystalline and amorphous cellulose during slow pyrolysis at low temperatures. Fuel 216:313-321. https://doi.org/10.1016/j.fuel.2017.11.083

Lin N, Dufresne A (2014) Surface chemistry, morphological analysis and properties of cellulose nanocrystals with gradient sulfation degrees. Nanoscale 6:5384-5393. https://doi.org/10.1039/C4NR00241E

Liu T, An QF, Wang XS, Zhao Q, Zhu BK, Gao CJ (2014) Preparation and properties of PEC nanocomposite membranes with carboxymethyl cellulose and modified silica. Carbohydr Polym 106:403-409. https://doi.org/10.1016/j. carbpol.2014.01.040

Lu P, Hsieh Y (2010) Preparation and properties of cellulose nanocrystals: rods, spheres, and network. Carbohydr Polym 82(2):329-336. https://doi.org/10.1016/j.carbpol. 2010.04.073

Ma X, Cheng Y, Qin X, Guo T, Deng J, Liu X (2017) Hydrophilic modification of cellulose nanocrystals improves the physicochemical properties of cassava starch-based nanocomposite films. LWT Food Sci Technol 86:318-326. https://doi.org/10.1016/j.lwt.2017.08.012

McMurry J (2013) Organic chemistry (chapter 2), 7th edn. Cengage Lernaning, São Paulo

Meng X, Edgar KJ (2015) Synthesis of amide-functionalized cellulose esters by olefin cross-metathesis. Carbohydr Polym 132:565-573. https://doi.org/10.1016/j.carbpol. 2015.06.052

Mirhosseini H, Tan CP, Hamid NSA, Yusof S (2008) Effect of arabic gum, xanthan gum and orange oil contents on $\zeta$ potential, conductivity, stability, size index and $\mathrm{pH}$ of 
orange beverage emulsion. Colloids Surf A 315:47-56. https://doi.org/10.1016/j.colsurfa.2007.07.007

Morais JPS, Rosa MF, Souza MSM, Nascimento LD, Nascimento DM, Cassales AR (2013) Extraction and characterization of nanocellulose structures from raw cotton linter. Carbohydr Polym 91(1):229-235. https://doi.org/10. 1016/j.carbpol.2012.08.010

Moreira S, Silva NB, Lima JA, Rocha HAO, Medeiros SRB, Alves Junior C, Gama FM (2009) BC nanofibres: in vitro study of genotoxicity and cell proliferation. Toxicol Lett 189:235-241. https://doi.org/10.1016/j.toxlet.2009.06.849

Mukarakate C, Mittal A, Ciesielski PN, Budhi S, Thompson L, Iisa K, Nimlos MR, Donohoe BS (2016) Influence of crystal allomorph and crystallinity on the products and behavior of cellulose during fast pyrolysis. ACS Sustain Chem Eng 4(9):4662-4674. https://doi.org/10.1021/ acssuschemeng.6b00812

Ng HM, Sin LT, Tee TT, Bee ST, Hui D, Low CY, Rahmat AR (2015) Extraction of cellulose nanocrystals from plant sources for application as reinforcing agent in polymers. Compos B 75:176-200. https://doi.org/10.1016/j. compositesb.2015.01.008

Nishiyama Y, Sugiyama J, Chanzy H, Langan P (2003) Crystal structure and hydrogen bonding system in cellulose $\mathrm{I} \alpha$ from synchrotron X-ray and neutron fiber diffraction. J Am Chem Soc 125(47):14300-14306. https://doi.org/10.1021/ ja037055w

Pecoraro E, Manzani D, Messaddeq Y, Ribeiro SJ (2008) Monomers, polymers and composites from renewable resources. Bacterial cellulose from Glucanacetobacter xylinus: preparation, properties and applications, 1 st edn. Elsevier, Oxford, pp 369-384

Pereira ALS, Nascimento DMD, de Souza Filho M, Sá M, Morais JPS, Vasconcelos NF, Feitosa JPA, de Rosa MF (2014) Improvement of polyvinyl alcohol properties by adding nanocrystalline cellulose isolated from banana pseudostems. Carbohydr Polym 112:165-172. https://doi. org/10.1016/j.carbpol.2014.05.090

Petersson L, Kvien I, Oksman K (2007) Structure and thermal properties of poly(lactic acid)/cellulose whiskers nanocomposite materials. Compos Sci Technol 67:2535-2544. https://doi.org/10.1016/j.compscitech. 2006.12.012

Picheth GF, Pirich CL, Sierakowski MR, Woehl MA, Sakakibara CN, Souza CF, Martin AA, Silva R, Freitas RA (2017) Bacterial cellulose in biomedical application: a review. Int J Biol Macromol 104:97-106. https://doi.org/ 10.1016/j.ijbiomac.2017.05.171

Pushpamalar V, Langford SJ, Ahmad M, Lim YY (2006) Optimization of reaction conditions for preparing carboxymethyl cellulose from sago waste. Carbohydr Polym 64:312-318. https://doi.org/10.1016/j.carbpol.2005.12. 003

Qi H, Liebert T, Meister F, Heinze T (2009) Homogenous carboxymethylation of cellulose in the $\mathrm{NaOH} /$ urea aqueous solution. React Funct Polym 69:779-784. https://doi.org/ 10.1016/j.reactfunctpolym.2009.06.007

Rachtanapun P, Luangkamin S, Tanprasert K, Suriyatem R (2012) Carboxymethyl cellulose film from durian rind. LWT Food Sci Technol 48:52-58. https://doi.org/10.1016/ j.lwt.2012.02.029
Ramírez JAA, Suriano CJ, Cerrutti P, Foresti ML (2014) Surface esterification of cellulose nanofibers by a simple organocatalytic methodology. Carbohydr Polym 114:416-423. https://doi.org/10.1016/j.carbpol.2014.08. 020

Roman M, Winter WT (2004) Effect of sulfate groups from sulfuric acid hydrolysis on the thermal degradation behavior of bacterial cellulose. Biomacromol 5:1671-1677. https://doi.org/10.1021/bm034519

Santos DM, Lacerda BA, Ascheri DPR, Signini R, Aquino GLB (2015) Microwave-assisted carboxymethylation of cellulose extracted from Brewer's spent grain. Carbohydr Polym 131:125-133. https://doi.org/10.1016/j.carbpol. 2015.05.051

Schatz C, Lucas JM, Viton C, Domard A, Pichot C, Delair T (2004) Formation and Properties of Positively Charged Colloids Based on Polyelectrolyte Complexes of Biopolymers. Langmuir 20(18):7766-7778. https://doi. org/10.1021/la049460m

Scherrer P (1918) Bestimmung der Größe und der inneren Struktur von Kolloidteilchen mittels Röntgenstrahlen. Nachrichten von der Gesellschaft der Wissenschaften zu Göttingen, Mathematisch-Physikalische Klasse, pp 98-100. http://resolver.sub.uni-goettingen.de/ purl?PPN252457811_1918. Accessed 5 Dec 2018.

Seabra AB, Bernardes JS, Fávaro WJ, Paula AJ, Durán N (2018) Cellulose nanocrystals as carriers in medicine and their toxicities: a review. Carbohydr Polym 181:515-527. https://doi.org/10.1016/j.carbpol.2017.12.014

Segal L, Creely J, Martin A, Conrad C (1959) An empirical method for estimating the degree of crystallinity of native cellulose using the X-ray diffractometer. Text Res J 29:786-794. 004051755902901003

Shang Q, Liu C, Hu Y, Jia P, Hu L, Zhou Y (2018) Bio-inspired hydrophobic modification of cellulose nanocrystals with castor oil. Carbohydr Polym 191:168-175. https://doi.org/ 10.1016/j.carbpol.2018.03.012

Shoda M, Sugano Y (2005) Recent advances in bacterial cellulose production. Biotechnol Bioprocess Eng 10:1-8. https://doi.org/10.1007/BF02931175

Song Y, Chen L (2015) Effect of net surface charge on physical properties of the cellulose nanoparticles and their efficacy for oral protein delivery. Carbohydr Polym 121:10-17. https://doi.org/10.1016/j.carbpol.2014.12.019

Sugiyama J, Persson J, Chanzy H (1991) Combined infrared and electron diffraction study of the polymorphism of native celluloses. Macromolecules 24(9):2461-2466. https://doi. org/10.1021/ma00009a050

Togrul H, Arslan N (2004) Carboxymethyl cellulose from sugar beet pulp cellulose as a hydrophilic polymer in coating of mandarin. J Food Eng 62:271-279. https://doi.org/10. 1016/S0260-8774(03)00240-1

Varma CAK, Koley RK, Singh S, Sen AK, Kumar KJ (2016) Homogeneous carboxymethylated orange pulp cellulose: characterization and evaluation in terms of drug delivery. Int J Biol Macromol 93:1141-1146. https://doi.org/10. 1016/j.ijbiomac.2016.09.084

Vasconcelos NF, Feitosa JPA, Gama FMP, Morais JPS, Andrade FK, Souza MSM, Rosa MF (2017) Bacterial cellulose nanocrystals produced under different hydrolysis 
conditions: properties and morphological features. Carbohydr Polym 155:425-431. https://doi.org/10.1016/j. carbpol.2016.08.090

Vehlow D, Schmidt R, Gebert A, Siebert M, Lips KS, Müller M (2016) Polyelectrolyte complex based interfacial drug delivery system with controlled loading and improved release performance for bone therapeutics. Nanomaterials 6(53):1-21. https://doi.org/10.3390/nano6030053

Wan Y, An F, Zhou P, Liu Y, Lu C, Chen H (2017) Effect of the polymorphs of cellulose on its pyrolysis kinetic and char yield. J Anal Appl Pyrolysis 127:223-228. https://doi.org/ 10.1016/j.jaap.2017.08.002

Wu H, Williams GR, Wu J, Wu J, Niu S, Li H, Zhu L (2018a) Regenerated chitin fibers reinforced with bacterial cellulose nanocrystals as suture biomaterials. Carbohydr Polym 180:304-313. https://doi.org/10.1016/j.carbpol.2017.10. 022

Wu Z, Xu J, Gong J, Li J, Mo L (2018b) Preparation, characterization and acetylation of cellulose nanocrystal allomorphs. Cellulose 25:4905-4918. https://doi.org/10.1007/ s10570-018-1937-6

Yamada Y, Yukphan P, Vu HTL, Muramatsu Y, Ochaikul D, Tanasupawat S, Nakagawa Y (2012) Description of Komagataeibacter gen. nov., with proposals of new combinations (Acetobacteraceae). J Gen Appl Microbiol 58:397-404. https://doi.org/10.2323/jgam.58.397

Yan H, Chen X, Song H, Li J, Feng Y, Shi Z, Lin Q (2017) Synthesis of bacterial cellulose and bacterial cellulose nanocrystals for their applications in the stabilization of olive oil pickering emulsion. Food Hydrocoll 72:127-135. https://doi.org/10.1016/j.foodhyd.2017.05.044

Yeasmin MS, Mondal MIH (2015) Synthesis of highly substituted carboxymethyl cellulose depending on cellulose particle size. Int J Biol Macromol 80:725-731. https://doi. org/10.1016/j.ijbiomac.2015.07.040

Zhou Y, Sun S, Bei W, Zahi MR, Yuan Q, Liang H (2018) Preparation and antimicrobial activity of oregano essential oil Pickering emulsion stabilized by cellulose nanocrystals. Int J Biol Macromol 112:7-13. https://doi.org/10.1016/j. ijbiomac.2018.01.102

Zugenmaier P (2008) Crystalline cellulose and derivatives: characterization and structure (chapter 5). Springer, Berlin. https://doi.org/10.1007/978-3-540-73934-0

Publisher's Note Springer Nature remains neutral with regard to jurisdictional claims in published maps and institutional affiliations. 